\title{
Differential diffusion effect on the stabilization characteristics of autoignited laminar lifted methane/hydrogen jet flames in heated coflow air
}

\author{
Ki Sung Jung, ${ }^{\mathrm{a}, 1}$, Seung Ook Kimª,1, Tianfeng Lu ${ }^{\mathrm{b}}$, Suk Ho Chung ${ }^{\mathrm{c}}$, Bok Jik Lee ${ }^{\mathrm{d}, *}$, Chun \\ Sang $\mathrm{Yoo}^{\mathrm{a}, *}$ \\ ${ }^{a}$ Department of Mechanical Engineering, Ulsan National Institute of Science and Technology, Ulsan 44919, \\ Republic of Korea \\ ${ }^{b}$ Department of Mechanical Engineering, University of Connecticut, Storrs, CT 06269, USA \\ ${ }^{c}$ Clean Combustion Research Center, King Abdullah University of Science and Technology, Thuwal, Saudi \\ Arabia \\ ${ }^{d}$ School of Mechanical Engineering, Gwangju Institute of Science and Technology, Gwangju 61005, \\ Republic of Korea
}

\begin{abstract}
The characteristics of autoignited laminar lifted methane/hydrogen jet flames in heated coflow air are numerically investigated using laminarSMOKE code with a 57-species detailed methane/air chemical kinetic mechanism. Detailed numerical simulations are performed for various fuel jet velocities, $U_{0}$, with different hydrogen ratio of the fuel jet, $R_{\mathrm{H}}$, and the inlet temperature, $T_{0}$. Based on the flame characteristics, the autoignited laminar lifted jet flames can be categorized into three regimes of combustion mode: the tribrachial edge flame regime, the Moderate or Intense Low-oxygen Dilution (MILD) combustion regime, and the transition regime in between. Under relatively low temperature and high hydrogen ratio $(\mathrm{LTHH})$ conditions, an unusual decreasing liftoff height, $H_{\mathrm{L}}$, behavior with increasing $U_{0}$ is observed, qualitatively similar to those of previous experimental observations. From additional simulations with modified hydrogen mass diffusivity, it is substantiated that the unusual decreasing $H_{\mathrm{L}}$ behavior is primarily attributed to the high diffusive nature of hydrogen molecules. The species transport budget, autoignition index, and displacement speed analyses verify that the autoignited lifted jet flames are stabilized by autoignition-assisted flame propagation or autoignition depending on the combustion regime. Chemical explosive mode analysis (CEMA) identifies important variables and reaction steps for the MILD
\end{abstract}


combustion and tribrachial edge flame regimes.

Keywords: Autoignition, liftoff height, flame stabilization, tribrachial edge flame, MILD combustion

\section{Introduction}

Numerous experimental and numerical studies of autoignition of various fuel/air mixtures have been conducted not only because it is one of the most important combustion phenomena $[1,2]$, but also because it appears in many practical combustion devices such as diesel engines, homogeneous charge compression ignition (HCCI) engine, and its variants [3-7]. In general, autoignition in an ideal HCCI engine occurs under adiabatic condition due to its homogeneities in both temperature and composition. However, autoignition in variants of HCCI combustion including stratified charge compression ignition (SCCI) [8, 9] and reactivity controlled compression ignition (RCCI) $[5,10,11]$ combustion occurs nonadiabatically due to their mixture stratification and/or direct-fuel injection to control overall ignition timing and mitigate excessive pressure rise rate (PRR) in an engine cylinder. Similarly, autoignition in the diesel combustion occurs non-adiabatically due to its inherent mixture stratification. Therefore, the liftoff characteristics and stabilization mechanisms of turbulent lifted jet flames at high pressures and temperatures have been a long-time research topic to understand the fundamentals of the diesel combustion $[1,3,12-14]$.

The characteristics of autoignited laminar lifted jet flames in heated coflow air have also been investigated due to their distinct features from those of non-autoignited lifted jet flames and their potential as a building-block configuration for understanding turbulent lifted jet flames at high pressures and temperatures. For instance, stabilization mechanisms found from autoignited laminar lifted flames under various conditions can be used to understand those of turbulent lifted jet flames featured by complicated and transient nature. Chung and coworkers [15-17] found that an autoignition kernel in a laminar nonpremixed fuel jet

\footnotetext{
*Corresponding authors.

Email addresses: bjlee@gist.ac.kr (Bok Jik Lee), csyoo@unist.ac.kr (Chun Sang Yoo)

${ }^{1}$ These authors contributed equally to this work. 
in heated coflow air can develop into a stationary lifted flame or a nozzle-attached flame depending on the inlet conditions of the fuel jet and coflow air. They also elucidated that a stationary autoignited laminar lifted jet flame can exist regardless of the Schmidt number of the fuel jet, which implies that ignition delay can play a critical role in stabilizing laminar lifted jet flame under autoignitive conditions [16]. A tribrachial edge flame, or Moderate or Intense Low-oxygen Dilution (MILD) combustion features in the autoignited laminar lifted jet flames; the former appears when the fuel mole fraction in the fuel jet, $X_{\mathrm{F}, 0}$, is relatively high while the latter occurs at relatively-low $X_{\mathrm{F}, 0}$. The leading edge of the autoignited laminar lifted jet flames with tribrachial edge consists of lean/rich premixed flame wings and a trailing nonpremixed flame [18]. However, when the fuel jet is excessively diluted with an inert gas such as nitrogen, the conventional tribrachial edge flame does not exist and its flame structure changes to that of a MILD combustion with faint blue color without exhibiting a clear tribrachial structure [15-21].

From previous studies of autoignited laminar lifted jet flames $[15,16]$, their liftoff height variation has been intensively investigated together with their flame structure characteristics. The liftoff height, $H_{\mathrm{L}}$, of autoignited laminar lifted jet flames is found to be functions of the fuel jet velocity, $U_{0}$, and the 0-D adiabatic ignition delay of the stoichiometric fuel/air mixture based on the inlet condition, $\tau_{\mathrm{ig}, \mathrm{st}}$ : i.e., $H_{\mathrm{L}} \sim U_{0} \tau_{\mathrm{ig}, \mathrm{st}}^{2}$. This correlation was originally devised by Choi et al. [15] considering thermal balance between heat release from autoignition and heat loss by diffusion in a jet mixing layer. As such, $H_{\mathrm{L}}$ increases with increasing $U_{0}$ for the same fuel and oxidizer jet conditions. This correlation is in good agreement with experimental data for autoignited lifted flames with tribrachial edge structure of various single component fuel jets [16]. For an autoignited lifted jet flame with a MILD combustion, the $H_{\mathrm{L}}$ correlation was modified incorporating the ignition strength of the fuel jet [16]: $H_{\mathrm{L}} \sim U_{0} \tau_{\mathrm{ig}, \mathrm{st}}^{2} Y_{\mathrm{F}, 0}$, where $Y_{\mathrm{F}, 0}$ is the fuel mass fraction at the inlet [16]. For both $H_{\mathrm{L}}$ correlations of tribrachial edge flames and MILD combustion, we can readily observe a quadratic dependence of $H_{\mathrm{L}}$ on $\tau_{\mathrm{ig}, \mathrm{st}}$, which implies that the adiabatic 0-D ignition delay can play a critical role in stabilizing autoignited laminar lifted jet flames.

In a previous experimental study of autoignited laminar lifted methane/hydrogen jet 
flames [17], however, an unusual liftoff height variation with $U_{0}$ was observed; $H_{\mathrm{L}}$ decreases with increasing $U_{0}$ at relatively-low inlet temperatures and relatively-high hydrogen content. As such, the decreasing $H_{\mathrm{L}}$ with $U_{0}$ does not follow the conventional autoignited laminar liftoff height behavior of $H_{\mathrm{L}} \sim U_{0}$. It was conjectured that the unusual $H_{\mathrm{L}}$ behavior might be attributed to differential diffusion between methane and hydrogen molecules in the fuel jet. Moreover, due to the unusual characteristics of the autoignited laminar lifted methane/hydrogen jet flames, another unique feature of the flames was identified that the flame structure changes from a lifted flame with tribrachial edge to a MILD combustion with decreasing $U_{0}$ although the fuel jet is not excessively diluted with an inert gas. According to previous studies of autoignited laminar lifted flames with a single component fuel such as methane and propane, the transition from a tribrachial edge flame to a MILD combustion was typically observed when the inlet fuel mole fraction is significantly low, or $X_{\mathrm{F}, 0} \sim O(0.01)[15,18]$. In the autoignition of methane/hydrogen jets in heated coflow air, however, a gradual transition from a tribrachial flame to a MILD combustion was observed with decreasing $U_{0}$ even though the fuel jet is not highly diluted with nitrogen $\left(X_{\mathrm{F}, 0} \sim\right.$ $O(0.1))$.

Therefore, the objective of the present study is two-fold: (1) to understand the liftoff characteristics of autoignited laminar lifted methane/hydrogen jet flames, especially the reason of the occurrence of the decreasing behavior of $H_{\mathrm{L}}$ with $U_{0}$, and (2) to elucidate the flame stabilization and structure characteristics of the autoignited laminar lifted jet flames by performing 2-D detailed numerical simulations for different inlet fuel jet conditions and hydrogen mass diffusivities. The MILD combustion featured by very faint blue flame has many advantages in reducing soot and NOx due to its low flame temperature, and in achieving high thermal efficiency through its high reactant temperature $[22,23]$. In the context of utilizing low flame temperature, the MILD combustion is quite similar to low temperature combustion (LTC) adopted in advanced IC engines. In the present study, therefore, the characteristics of autoignited laminar lifted flames with MILD combustion will also be investigated. 


\section{Numerical methods}

Detailed numerical simulations of autoignited laminar lifted methane/hydrogen nonpremixed jet flames in heated coflow air are performed in an axisymmetric coflow burner configuration, which has been adopted in several previous experimental and numerical studies [15-18, 21]. The steady compressible Navier-Stokes, species continuity, and energy equations are solved using laminarSMOKE [24, 25], which is an open-source code based on OpenFOAM [26] for simulations of multi-dimensional compressible laminar reacting flows with skeletal/detailed chemical mechanisms. For the detailed description of laminarSMOKE, readers are referred to $[24,25]$.

Figure 1 shows a schematic of the computational domain adopted in this study. The domain size is $6.65 \mathrm{~cm} \times 50 \mathrm{~cm}$ in the radial $r$ - and the axial $z$-directions. The inner diameter and thickness of the fuel nozzle are $3.76 \mathrm{~mm}$ and $0.5 \mathrm{~mm}$, respectively. To take into account the effect of the finite thickness of the fuel jet nozzle on the flow, $3 \mathrm{~cm}$ long fuel nozzle is added to the main computational domain, which protrudes $1 \mathrm{~cm}$ above the coflow air inlet as shown in Fig. 1. Note that the configuration of the computational domain is identical to those of previous experiments and simulations [15-18, 21].

No-slip and adiabatic boundary conditions are used for all the solid boundaries and symmetric boundary conditions are used for $r=0$. For the inlets, the fuel inlet velocity is specified as that of a fully-developed pipe flow for which the mean velocity is $U_{0}$, and the coflow air velocity, $U_{\mathrm{C}}$, is set to be $1.1 \mathrm{~m} / \mathrm{s}$. For both fuel and air inlets, constant inlet temperature, $T_{0}$, is specified. For the outlet, zero-gradient outflow boundary conditions are used. For all simulations, the pressure is atmospheric and the methane/hydrogen fuel jet is diluted with nitrogen such that the fuel mole fraction at the inlet, $X_{\mathrm{F}, 0}$, is 0.2 . In the $r$-direction, a uniform grid space of $100 \mu \mathrm{m}$ is used for $0 \leq r \leq 1.5 \mathrm{~cm}$ to resolve the flame structure and a stretched grid is applied to the remaining domain. In the $z$-direction, the same uniform grid of $100 \mu \mathrm{m}$ is used. Figure 2 shows profiles of axial velocity, temperature, and mass fractions of $\mathrm{CH}_{2} \mathrm{O}$ and $\mathrm{OH}$ of a lifted methane/hydrogen jet flame along the stoichiometric mixture fraction, $\xi_{\mathrm{st}}$, isoline for three different grid resolutions, which verifies 


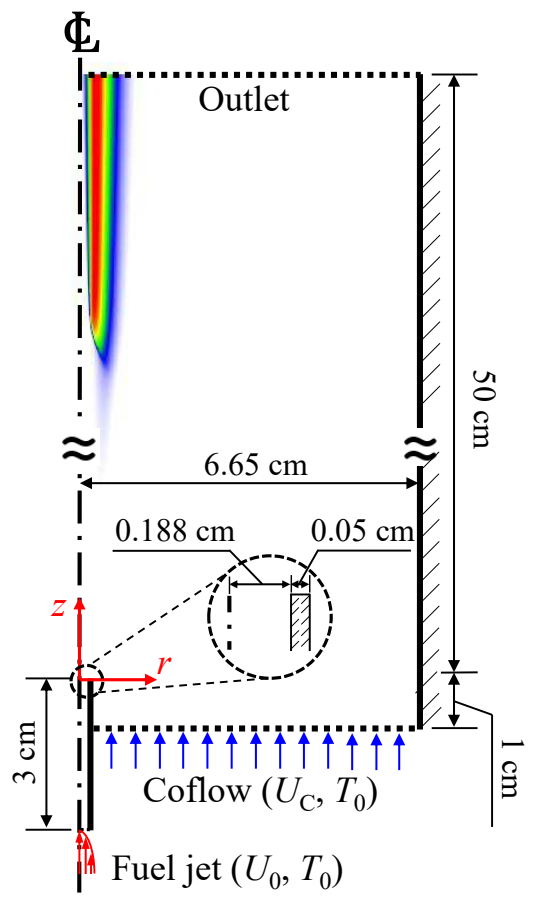

Figure 1: Schematic of the computational domain for simulations of autoignited laminar lifted methane/hydrogen jet flames in heated coflow air. 
that the current grid size of $100 \mu \mathrm{m}$ can reasonably resolve the profiles compared to a fine grid size of $50 \mu \mathrm{m}$. The flame thickness, $\delta_{f} \equiv\left(T_{\max }-T_{\min }\right) / \max (d T / d x)$, along the stoichiometric mixture fraction, $\xi_{\mathrm{st}}$, isoline is found to be approximately $2 \mathrm{~mm}$. Thus, the current grid space of $100 \mu \mathrm{m}$ can resolve the flame thickness with approximately 20 grids, which is sufficient to capture the flame structure and liftoff characteristics of autoignited laminar lifted methane/hydrogen flames. Even though the lifted flames are very thick under the present conditions, their rich premixed flame regions may not be sufficiently resolved by the current $100 \mu \mathrm{m}$ grids, which may influence the molecular diffusion and/or other processes. However, we found that the overall flame structure and stabilization characteristics of the current grid resolution are nearly identical to those of the fine grid resolution of $50 \mu \mathrm{m}$, and as such, we believe that the effect of the unresolved part of the rich premixed flame region on the molecular diffusion is minimal if it exists. Note that the San Diego mechanism with 57 species [27] was used for the simulations. Also note that from a series of 0-D simulations of methane/hydrogen/nitrogen mixtures under the present simulation conditions using CHEMKIN [28], it is found that the decomposition of $\mathrm{CH}_{4}$ and $\mathrm{H}_{2}$ in the fuel nozzle rarely occurs and hence, does not affect the present simulation results.

We initialize a lifted flame with high $U_{0}$ without applying any external ignition source (i.e., literally autoignition). Then, we adjust $U_{0}$ to obtain the liftoff height for other cases. In experiments, the autoignited liftoff height is repeatable. This implies that a liftoff height of an autoignited lifted flame is identical to that of a lifted flame obtained from another autoignited steady liftoff flame by changing the fuel jet velocity, which can be considered as a forced ignition. Otherwise, the liftoff height would not be repeatable. To further clarify whether final stabilization location and its stabilization mechanism depend on the initialization or not, we performed several transient numerical simulations of methane/hydrogen jet flames (not shown here). The flames locally autoignite and are soon stabilized at the same locations of the corresponding steady cases, which verifies that the lifted flames in the present simulation are autoignitable and the liftoff heights are also repeatable. 

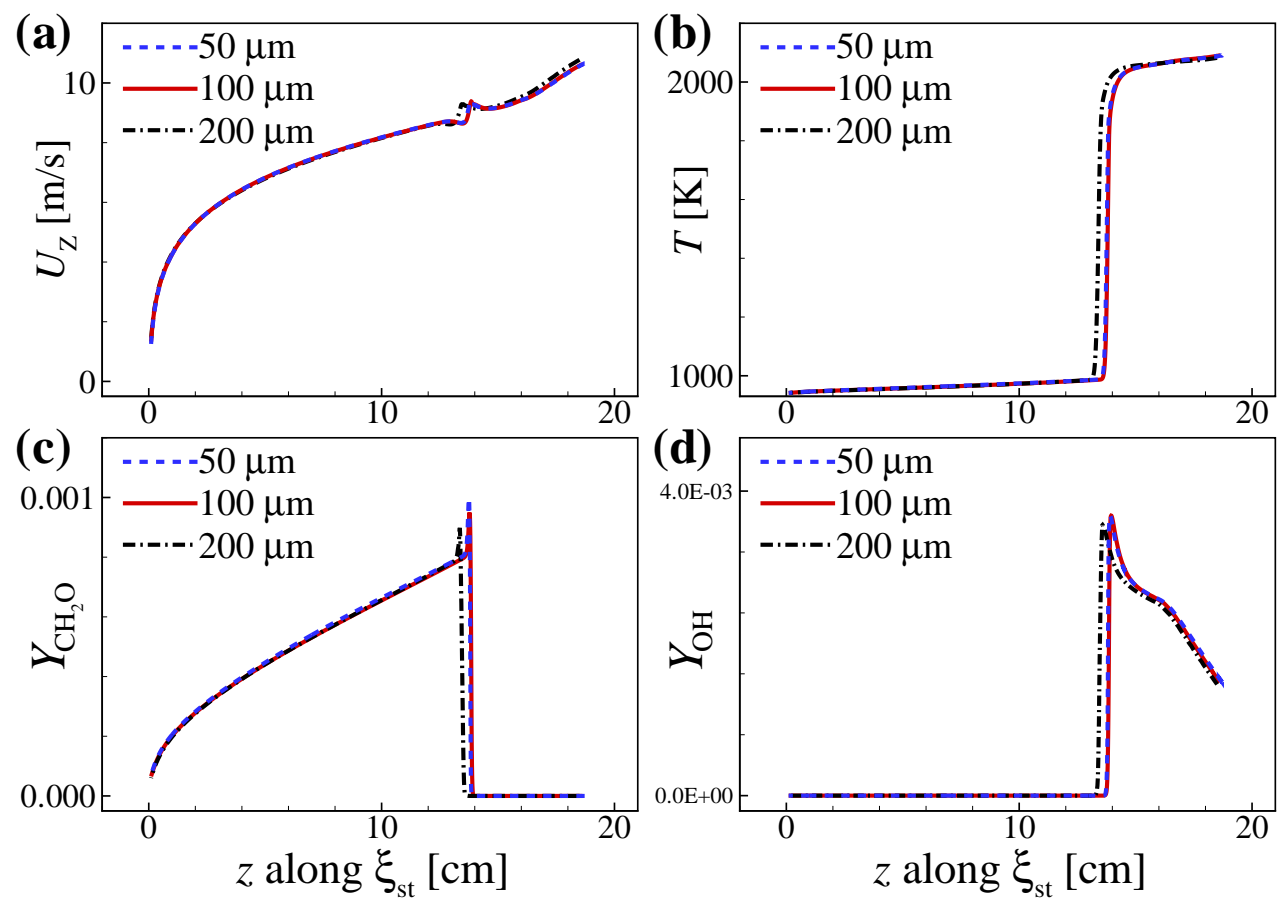

Figure 2: Profiles of (a) axial velocity, (b) temperature, and mass fractions of (c) $\mathrm{CH}_{2} \mathrm{O}$ and (d) $\mathrm{OH}$ of a lifted methane/hydrogen jet flame along the stoichiometric mixture fraction, $\xi_{\text {st }}$, isoline for three different grid resolutions. The inlet temperature and velocity of the fuel jet are $940 \mathrm{~K}$ and $15 \mathrm{~m} / \mathrm{s}$, respectively, and the hydrogen volume fraction of the fuel jet is 0.35 . 


\section{Overall characteristics of the lifted flames}

In previous experiments [17], the decreasing behavior of $H_{\mathrm{L}}$ with increasing $U_{0}$ occurs under relatively-low $T_{0}$ conditions $\left(860<T_{0}<920 \mathrm{~K}\right)$ together with relatively-high hydrogen ratio in the fuel $\left(R_{\mathrm{H}}>0.12\right)$. The hydrogen ratio, $R_{\mathrm{H}}$, is defined as $R_{\mathrm{H}}=X_{\mathrm{H}_{2}} /\left(X_{\mathrm{CH}_{4}}+X_{\mathrm{H}_{2}}\right)$, where $X_{\mathrm{H}_{2}}$ and $X_{\mathrm{CH}_{4}}$ represent the mole fractions of hydrogen and methane in the fuel jet, respectively. Under relatively-high $T_{0}$ and low $R_{\mathrm{H}}$ conditions, however, the opposite trend of the liftoff height can be observed (i.e., $H_{\mathrm{L}} \sim U_{0}$ ). To numerically simulate the two different trends of the liftoff height variation, we chose two simulation conditions through several simulation tests: (1) relatively-high $T_{0}=1100 \mathrm{~K}$ and low $R_{\mathrm{H}}=0.05$; henceforth, it is denoted as the high temperature low hydrogen (HTLH) condition, and (2) relatively-low $T_{0}=940 \mathrm{~K}$ and high $R_{\mathrm{H}}=0.35$, which is denoted as the low temperature high hydrogen (LTHH) condition. Note that $T_{0}$ for both conditions are higher than those of previous experiments, which will be discussed in the following section.

\subsection{Chemical kinetic mechanisms}

From previous numerical studies of autoignited laminar lifted jet flames [18, 29], it was reported that $T_{0}$ of numerical simulations needs to be raised by approximately $100 \mathrm{~K}$ compared to that of experiments to obtain comparable $H_{\mathrm{L}}$ behavior. It was conjectured that this temperature discrepancy might be attributed to the inaccuracy of the chemical kinetic mechanism/transport data and/or experimental measurements. To select a proper chemical mechanism for the present study, therefore, we first tested several different methane oxidation mechanisms $[27,30-33]$ by evaluating their stoichiometric laminar burning velocity, $S_{\mathrm{L}}$, and $0-\mathrm{D}$ ignition delays, $\tau_{\mathrm{ig}}^{0}$.

Figure 3 shows $S_{\mathrm{L}}$ and $\tau_{\mathrm{ig}}^{0}$ of a stoichiometric methane/hydrogen/air mixture with $X_{\mathrm{F}, 0}=$ 0.2 and $R_{\mathrm{H}}=0.35$ as a function of the inlet or initial temperature. It is readily observed that

$S_{\mathrm{L}}$ increases and $\tau_{\text {ig }}^{0}$ decreases with increasing temperature as expected. However, $\tau_{\text {ig }}^{0}$ exhibits nearly an order of magnitude difference among the mechanisms for given temperature while $S_{\mathrm{L}}$ shows reasonable agreement, say, less than $10 \%$ difference at high temperatures relevant to the present simulation conditions. 

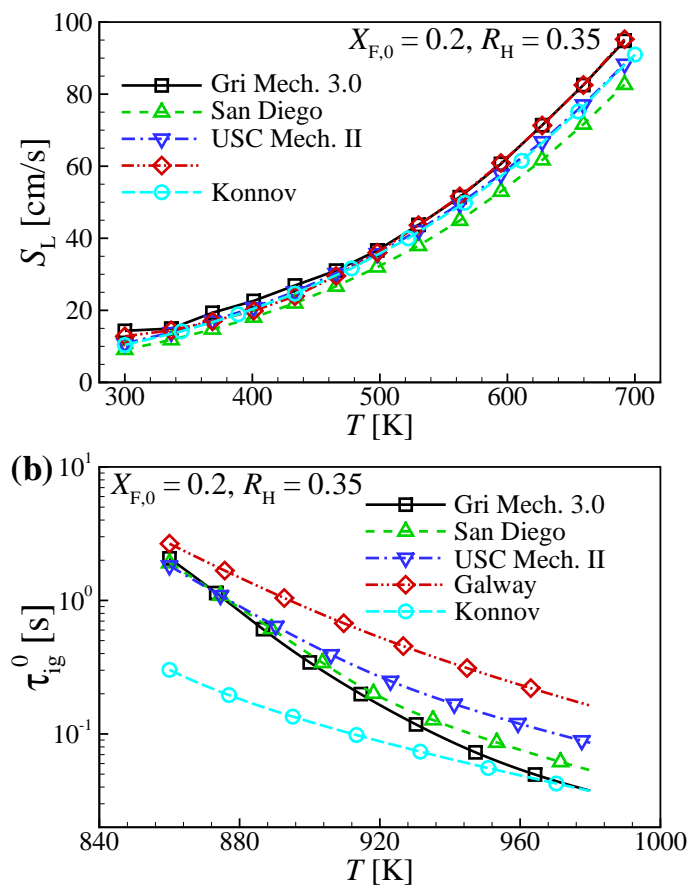

Figure 3: Variations of (a) laminar burning velocity, $S_{\mathrm{L}}$, and (b) 0-D ignition delay, $\tau_{\mathrm{ig}}^{0}$, of a stoichiometric methane/hydrogen/air mixture with $X_{\mathrm{F}, 0}=0.2$ and $R_{\mathrm{H}}=0.35$ as a function of the inlet or initial temperature for several different chemical kinetic mechanisms including GRI-3.0 [30], San Diego [27], USC-II [31], Galway [32], and Konnov [33] mechanisms.

These results can be attributed to inherent issues in developing a kinetic mechanism. A kinetic mechanism is typically validated for laminar burning velocities under atmospheric or mildly high pressures while it is done for ignition delays at high pressures due to the time limit of shock tube experiments $(\sim O(1 \mathrm{~ms}))$. Thus, at the present atmospheric pressure condition, the mechanisms may not be accurate enough to predict ignition delays of $\sim O(1$ s). The characteristics of $\tau_{\text {ig }}^{0}$ at atmospheric and high pressures for different chemical kinetics mechanisms are further examined and the results are reported in the supplementary material, which shows that the variation of $\tau_{\mathrm{ig}}^{0}$ among the kinetic mechanisms becomes significant under the atmospheric pressure condition.

Since the characteristics of autoignited laminar lifted flames are significantly affected by both $S_{\mathrm{L}}$ and $\tau_{\text {ig }}^{0}$, we can expect that their numerical $H_{\mathrm{L}}$ values will appreciably vary 


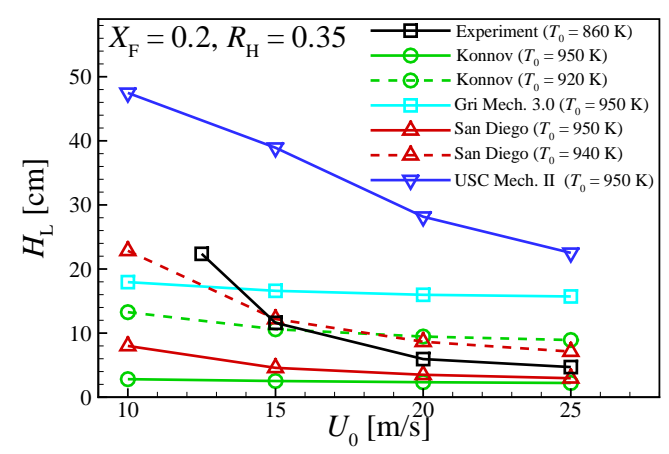

Figure 4: Variation of the liftoff height, $H_{\mathrm{L}}$, of autoignited laminar lifted methane/hydrogen jet flames with $X_{\mathrm{F}, 0}=0.2$ and $R_{\mathrm{H}}=0.35$ as a function of the inlet velocity, $U_{0}$, for several different chemical kinetic mechanisms and $T_{0}$.

depending on the chemical kinetic mechanisms. To evaluate the dependence of $H_{\mathrm{L}}$ on the choice of chemical kinetic mechanism, we performed 2-D numerical simulations of autoignited laminar lifted methane/hydrogen jet flames under the LTHH condition using four different chemical kinetic mechanisms and determined their $H_{\mathrm{L}}$ values as a function of $U_{0}$ as shown in Fig. 4. Note that we first tested the four different chemical mechanisms at $T_{0}=950$ $\mathrm{K}$ that is larger than the corresponding temperature of $860 \mathrm{~K}$ in the previous experiments [17]. This is because we could capture autoignited lifted jet flames within the computational domain with $T_{0}=950 \mathrm{~K}$. Among the four mechanisms, we selected the Konnov [33] and San Diego [27] mechanisms because their $H_{\mathrm{L}}$ were expected to show a better agreement with the experimental data for lower $T_{0}$. Then, we carried out additional simulations by decreasing $T_{0}$ for the two mechanisms to quantitatively match $H_{\mathrm{L}}$ to the experimental data as much as possible. Finally, we adopted the San Diego mechanism [27] for the following simulations.

It is readily observed from the result that even if there exists significant difference in $H_{\mathrm{L}}$ values, the decreasing tendency of $H_{\mathrm{L}}$ with $U_{0}$ under the LTHH condition remains the same for all the chemical kinetic mechanisms with different $T_{0}$. Since the characteristics of autoignited lifted laminar methane/hydrogen jet flames are found to be qualitatively consistent with those of experiments for all the chemical mechanisms, we believe that the present simulations can properly elucidate the physico-chemical mechanism behind the decreasing 
$H_{\mathrm{L}}$ behavior observed from the experiments.

\subsection{Lifted jet flames under HTLH condition}

Figure 5 shows the isocontours of temperature and mass fractions of $\mathrm{OH}, \mathrm{CH}_{2} \mathrm{O}$, and $\mathrm{H}_{2} \mathrm{O}_{2}$ of autoignited laminar lifted methane/hydrogen jet flames for various fuel jet velocities under the HTLH condition (i.e. $T_{0}=1100 \mathrm{~K}$ and $R_{\mathrm{H}}=0.05$ ). The dashed and dashdotted lines represent the mixture fraction isoline passing through the flamebase, $\xi_{\mathrm{fb}}$, and the stoichiometric mixture fraction isoline, $\xi_{\mathrm{st}}(=0.325)$, respectively. In the present study, $\xi$ is calculated based on Bilger's mixture fraction formula [34] and the flamebase is defined as the most upstream point of $Y_{\mathrm{OH}}=2.9 \times 10^{-4}$ isoline. The corresponding liftoff height is determined as the axial length from the fuel nozzle to the flamebase. Note that $Y_{\mathrm{OH}}=2.9$ $\times 10^{-4}$ isoline represents approximately $5 \%$ of its maximum increase in the domain, which is consistent with definitions used in previous studies $[13,14]$. It is readily observed that the flame is attached to the fuel nozzle up to, say, $U_{0}=25 \mathrm{~m} / \mathrm{s}$ and becomes lifted for higher $U_{0}$. Once the flame is lifted, the liftoff height increases with increasing $U_{0}$. These are in qualitative agreement with previous experimental results [17].

Under this condition, the flamebase lies at a fuel-lean mixture as observed in previous studies of laminar/turbulent lifted flames in heated coflows [13, 14, 18, 35]. The shifting of the flamebase to the fuel-lean mixture implies that the stabilization mechanism of autoignited laminar lifted flames would be different from that of non-autoignited laminar lifted flames in which the flamebase coincides with a point of the stoichiometric mixture line where the edge flame propagation speed balances local flow velocity [36, 37]. Although the lifted flame is stabilized at the fuel-lean mixture, the maximum temperature and mass fraction of $\mathrm{OH}$ occur following the stoichiometric mixture line downstream of the flamebase, similar to previous numerical results $[13,14,18,29]$.

The isocontours of mass fraction of $\mathrm{CH}_{2} \mathrm{O}$ and $\mathrm{H}_{2} \mathrm{O}_{2}$ are also shown in Fig. 5b to further identify the role of autoignition on the lifted flames. $\mathrm{CH}_{2} \mathrm{O}, \mathrm{HO}_{2}$, and $\mathrm{H}_{2} \mathrm{O}_{2}$ are important intermediate species during the early stage of hydrocarbon/air autoignition process, featuring that their concentrations attain their own peaks prior to the thermal ignition $[14,38,39]$. 

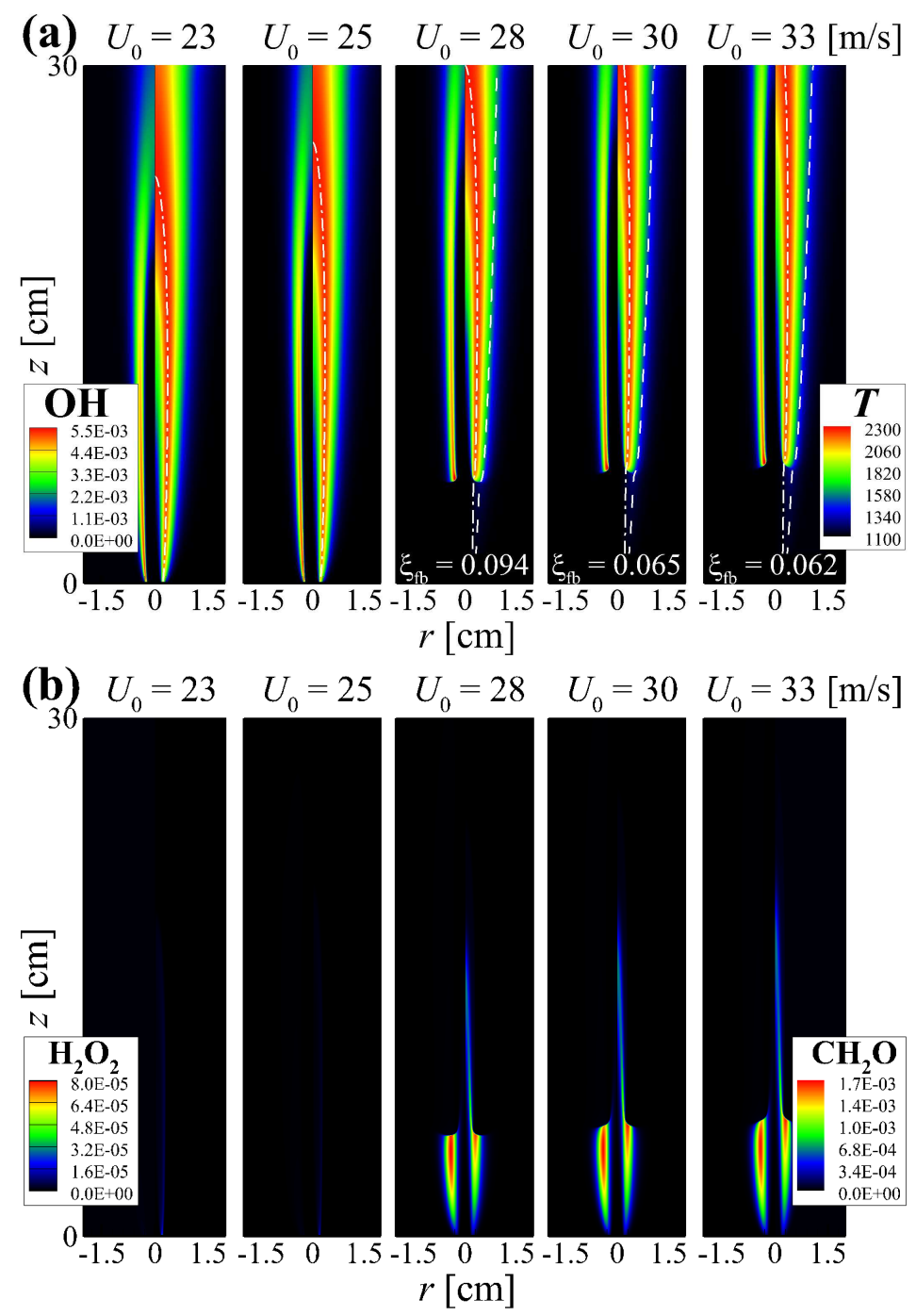

Figure 5: Isocontours of (a) $Y_{\mathrm{OH}}$ (left half) and $T$ (right half) and (b) $Y_{\mathrm{H}_{2} \mathrm{O}_{2}}$ (left half) and $Y_{\mathrm{CH}_{2} \mathrm{O}}$ (right half) for autoignited laminar lifted methane/hydrogen jet flames for various fuel jet velocities $U_{0}$ under the HTLH condition ( $T_{0}=1100 \mathrm{~K}$ and $\left.R_{\mathrm{H}}=0.05\right)$. The dashed and dash-dotted lines in (a) represent the mixture fraction isoline passing through the flamebase, $\xi_{\mathrm{fb}}$, and the stoichiometric mixture fraction isoline, $\xi_{\mathrm{st}}(=0.325)$, respectively. 
As such, they are regarded as precursors of autoignition. It is readily observed from the figure that $\mathrm{CH}_{2} \mathrm{O}$ and $\mathrm{H}_{2} \mathrm{O}_{2}$ are predominant upstream of the flamebase, which indicates that autoignition plays an important role in stabilizing the lifted flames [13, 14, 18]. Although not shown in here, $\mathrm{HO}_{2}$ behaves similarly to $\mathrm{H}_{2} \mathrm{O}_{2}$. Note that for non-autoignited lifted flames with low ambient temperature, $\mathrm{CH}_{2} \mathrm{O}$ only exists near the premixed flame wing when a flame is stabilized by the balance of the propagation speed of edge flame and local flow velocity [20].

To summarize the overall characteristics of the lifted flames under the HTLH condition, the variations of $H_{\mathrm{L}}$ and $\left(T_{\max }-T_{0}\right) / T_{\mathrm{ig}}$ as a function of $U_{0}$ are shown in Fig. 6. For comparison purpose, $H_{\mathrm{L}}$ variations from experiments [17] are also shown in the figure. $T_{\max }$ is the maximum flame temperature in the domain and $T_{\mathrm{ig}}$ is the minimum temperature for autoignition of the stoichiometric mixture based on the inlet conditions. We determine that autoignition occurs within the computational domain if the ignition delay at $T_{0}=T_{\mathrm{ig}}$ is less than one-jet flow-through time of the coflow air. Under the HTLH condition, $T_{\mathrm{ig}}$ is approximately $990 \mathrm{~K}$ from 0-D ignition tests using CHEMKIN [28].

In general, a combustion process can be defined as a MILD combustion when the following conditions are satisfied [23, 40]: (1) the inlet temperature of a reactant mixture is higher than its autoignition temperature, $T_{0}>T_{\mathrm{ig}}$, and (2) the maximum allowable temperature increase with respect to the inlet temperature is lower than its autoignition temperature, $\left(T_{\max }-T_{0}\right) / T_{\mathrm{ig}}<1$. For the present simulation cases, $T_{0}$ is greater than $T_{\mathrm{ig}}$, and as such, we adopt $\left(T_{\max }-T_{0}\right) / T_{\text {ig }}$ to identify the combustion mode of the lifted flames: a lifted flame with tribrachial edge occurs when $\left(T_{\max }-T_{0}\right) / T_{\mathrm{ig}}>1$ while a lifted flame with MILD combustion appears when $\left(T_{\max }-T_{0}\right) / T_{\text {ig }}<1$ is satisfied $[15,23,40,41]$. As shown in Fig. 6 , $\left(T_{\max }-T_{0}\right) / T_{\text {ig }}$ is well above unity and $T_{0}$ is great than $T_{\text {ig }}$, which indicates that only lifted flames with tribrachial edge appear under the HTLH condition.

\subsection{Lifted jet flames under LTHH condition}

To capture the overall features of autoignited laminar lifted methane/hydrogen jet flames under the LTHH condition (i.e. $T_{0}=940 \mathrm{~K}$ and $R_{\mathrm{H}}=0.35$ ), their temperature and the 


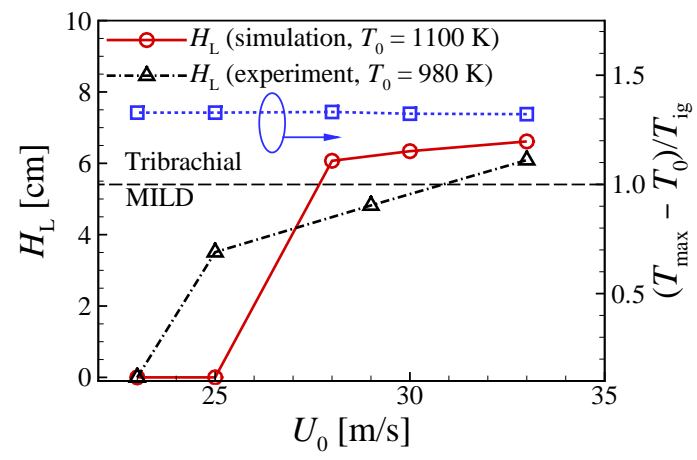

Figure 6: Variations of $H_{\mathrm{L}}$ (red) and $\left(T_{\max }-T_{0}\right) / T_{\mathrm{ig}}$ (blue) as a function of $U_{0}$ for autoignited laminar lifted methane/hydrogen jet flames under the HTLH condition $\left(T_{0}=1100 \mathrm{~K}\right.$ and $\left.R_{\mathrm{H}}=0.05\right)$. The black dash-dotted line represents $H_{\mathrm{L}}$ variation of the corresponding experiments [17].

mass fraction of $\mathrm{OH}, \mathrm{CH}_{2} \mathrm{O}$, and $\mathrm{H}_{2} \mathrm{O}_{2}$ isocontours for various fuel jet velocities $\left(U_{0}=4 \sim\right.$ $30 \mathrm{~m} / \mathrm{s}$ ) are shown in Fig. 7. Contrary to the cases under the HTLH condition, it is readily observed that $H_{\mathrm{L}}$ decreases with increasing $U_{0}$. Moreover, we cannot observe any nozzleattached flames within the test range of $U_{0}$. As mentioned above, this unusual decreasing $H_{\mathrm{L}}$ behavior has been experimentally observed in [17].

To understand the lifted flame characteristics under the LTHH condition, the variations of $H_{\mathrm{L}}$ and $\left(T_{\max }-T_{0}\right) / T_{\mathrm{ig}}$ as a function of $U_{0}$ are shown in Fig. 8, where $T_{\mathrm{ig}}$ is approximately $895 \mathrm{~K}$ under the LTHH condition. For comparison purpose, the corresponding experimental $H_{\mathrm{L}}$ variation [17] is also shown in the figure. Several points are noted from Figs. 7 and 8. First, the maximum temperature represented by $\left(T_{\max }-T_{0}\right) / T_{\mathrm{ig}}$ varies significantly for cases with $U_{0} \leq 10 \mathrm{~m} / \mathrm{s}$, in which the stoichiometric contour height is lower than the flamebase where autoignition is governed by fuel-lean mixtures. Moreover, $\left(T_{\max }-T_{0}\right) / T_{\mathrm{ig}}$ first falls below unity at $U_{0}=10 \mathrm{~m} / \mathrm{s}$ as $U_{0}$ decreases and the overall flame structure changes from a lifted flame with tribrachial edge to a lifted flame with MILD combustion.

Based on the flame structure characteristics such as the location of the flamebase relative to the centerline and $\left(T_{\max }-T_{0}\right) / T_{\text {ig }}$ values, we can classify the lifted flames under the LTHH condition into three different regimes as a function of $U_{0}$ : (1) the lifted flame with tribrachial edge for $\left(T_{\max }-T_{0}\right) / T_{\mathrm{ig}}>1$ (henceforth, denoted by the tribrachial edge flame regime; $U_{0}=$ 

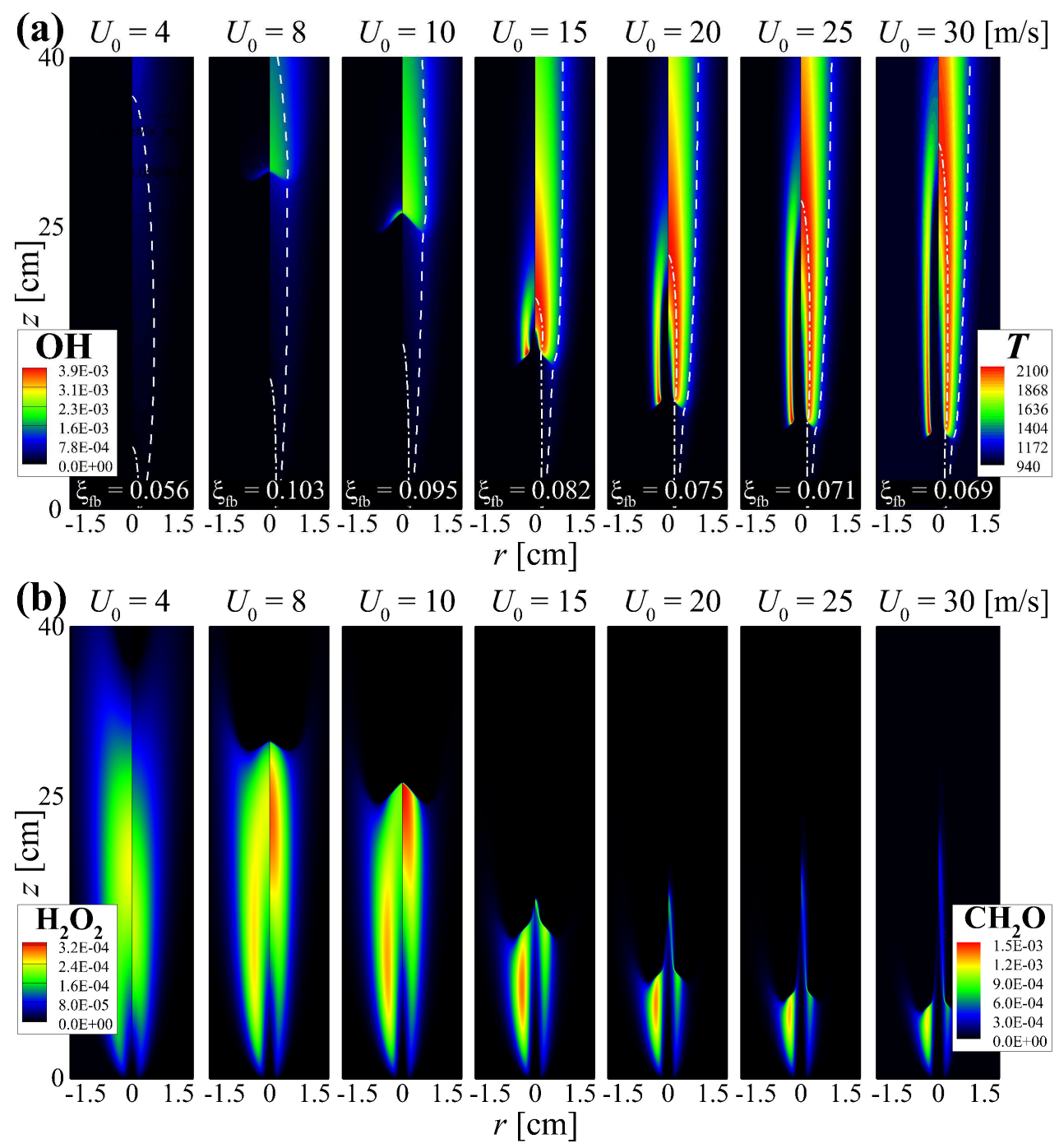

Figure 7: Isocontours of (a) $Y_{\mathrm{OH}}$ (left half) and $T$ (right half) and (b) $Y_{\mathrm{H}_{2} \mathrm{O}_{2}}$ (left half) and $Y_{\mathrm{CH}_{2} \mathrm{O}}$ (right half) for autoignited laminar lifted methane/hydrogen jet flames for various fuel jet velocities $U_{0}$ under the LTHH condition ( $T_{0}=940 \mathrm{~K}$ and $\left.R_{\mathrm{H}}=0.35\right)$. The dashed and dash-dotted lines in (a) represent the mixture fraction isoline passing through the flamebase, $\xi_{\mathrm{fb}}$, and the stoichiometric mixture fraction isoline, $\xi_{\text {st }}(=0.378)$, respectively. 


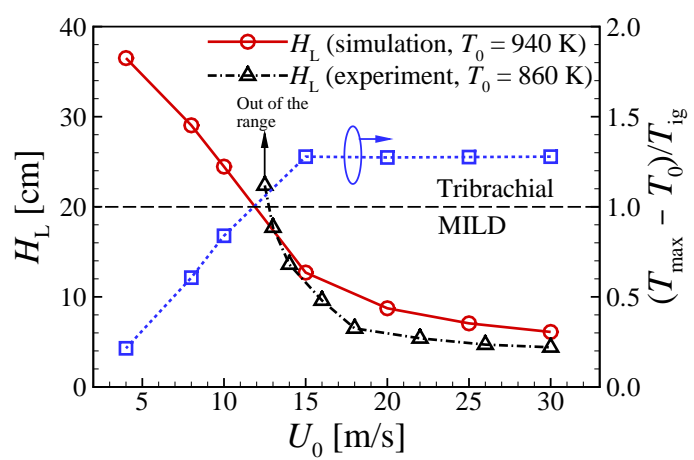

Figure 8: Variations of $H_{\mathrm{L}}$ (red) and $\left(T_{\max }-T_{0}\right) / T_{\mathrm{ig}}$ (blue) as a function of $U_{0}$ for autoignited lifted flames under the LTHH condition $\left(T_{0}=940 \mathrm{~K}\right.$ and $\left.R_{\mathrm{H}}=0.35\right)$. The black dash-dotted line represents $H_{\mathrm{L}}$ variation of the corresponding experiments [17]

$15 \sim 30 \mathrm{~m} / \mathrm{s})$, (2) the lifted flame with MILD combustion for $\left(T_{\max }-T_{0}\right) / T_{\mathrm{ig}}<1$ with the flamebase being located at the centerline (the MILD combustion regime; $U_{0}=4 \mathrm{~m} / \mathrm{s}$ ), and (3) the transition regime between the tribrachial edge flame and MILD combustion regimes for $\left(T_{\max }-T_{0}\right) / T_{\mathrm{ig}}<1$ with the flamebase being located radially outside the centerline (the transition regime; $U_{0}=8 \sim 10 \mathrm{~m} / \mathrm{s}$ ). Figure 9 shows the isocontours of heat release rate for $U_{0}=4$ and $15 \mathrm{~m} / \mathrm{s}$ under the LTHH condition, which represent the MILD combustion and tribrachial edge flame regimes, respectively. We can readily observe two different flame structures for different $U_{0}$; in the MILD combustion regime $\left(U_{0}=4 \mathrm{~m} / \mathrm{s}\right)$, the flame is relatively weak and blunt and the stoichiometric mixture fraction, $\xi_{\text {st }}$, isoline does not cross the flame region since it is overall very lean; while in the tribrachial edge flame regime $\left(U_{0}\right.$ $=15 \mathrm{~m} / \mathrm{s}$ ), it exhibits rich/lean premixed wings and a trailing nonpremixed flame which is along the $\xi_{\text {st }}$ isoline.

Second, for all the lifted jet flames, important intermediate species including $\mathrm{CH}_{2} \mathrm{O}, \mathrm{HO}_{2}$, and $\mathrm{H}_{2} \mathrm{O}_{2}$ are predominant in the upstream region from the flamebase, which indicates that autoignition affects the stabilization of the lifted flames. Moreover, $H_{\mathrm{L}}$ decreases significantly with increasing $U_{0}$ in the MILD combustion/transition regimes, whereas the decreasing tendency of $H_{\mathrm{L}}$ is mitigated in the tribrachial edge flame regime. From these results, it can be hypothesized that the unusual decreasing behavior of $H_{\mathrm{L}}$ under the LTHH condition 


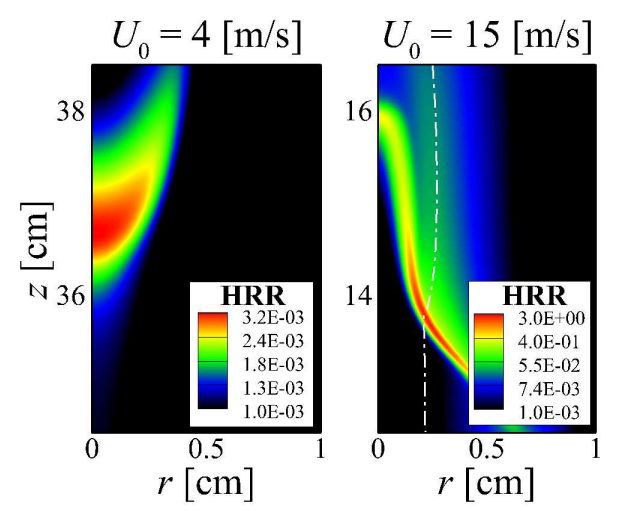

Figure 9: Isocontour of heat release rate $\left(\mathrm{J} / \mathrm{mm}^{3} \mathrm{~s}\right)$ for autoignited laminar lifted methane/hydrogen jet flames with $U_{0}=4$ (left) and $15 \mathrm{~m} / \mathrm{s}$ (right) under the LTHH condition. The dash-dotted line represents the stoichiometric mixture fraction isoline, $\xi_{\mathrm{st}}$.

would be attributed to the characteristics of autoignition and flame structure depending on the hydrogen content in the fuel jet, which will be further discussed later.

Note that under the LTHH condition, the flamebase is defined as the most upstream point of $Y_{\mathrm{OH}}=2.3 \times 10^{-4}$ isoline. For the MILD combustion regime, however, we cannot define the flamebase using such definition because the lifted flames with MILD combustion would not exhibit the conventional flame structure and $Y_{\mathrm{OH}}$ values remain below $2.3 \times 10^{-4}$. To avoid ambiguity in the flamebase definition, therefore, we adopt the chemical explosive mode analysis (CEMA) and define the flamebase as the most upstream point of $\operatorname{Re}\left(\lambda_{\mathrm{e}}\right)$ $=0$ isoline, where $\lambda_{\mathrm{e}}$ is an eigenvalue of the Jacobian of the chemical source term in the discretized governing equations [42-45]. In other words, a mixture with $\operatorname{Re}\left(\lambda_{\mathrm{e}}\right)>0$ is more apt to ignite while a mixture with $\operatorname{Re}\left(\lambda_{\mathrm{e}}\right)<0$ is already burned or fails to ignite. Therefore, $\operatorname{Re}\left(\lambda_{\mathrm{e}}\right)=0$ isoline can be used to discern between the burned and unburned mixtures in autoignition and delineate the flame front especially for the lean premixed fronts. For the tribrachial edge flame regime, the flamebase defined by $Y_{\mathrm{OH}}=2.3 \times 10^{-4}$ is nearly identical to that by the CEMA. The chemical features of the lifted jet flames under the LTHH condition using CEMA will be addressed in Section 5 . 


\section{Effect of hydrogen on the liftoff characteristics}

As mentioned above, Choi et al. [17] conjectured that the unusual decreasing behavior of $H_{\mathrm{L}}$ with increasing $U_{0}$ might be attributed to the disparity in mass diffusivities between methane and hydrogen. This hypothesis was based on observation that $H_{\mathrm{L}}$ varies significantly at relatively-low jet velocities that provide enough flow time to amplify the differential diffusion effect on the stabilization of the laminar lifted jet flames. To test whether or not the high diffusive nature of hydrogen molecules induces the unusual decreasing $H_{\mathrm{L}}$ tendency, we performed additional numerical simulations by artificially changing the mass diffusivity of hydrogen molecule, $D_{\mathrm{H}_{2}}$, to that of methane.

\subsection{Effect of hydrogen mass diffusivity on $H_{\mathrm{L}}$}

Figure 10 shows the isocontours of temperature and mass fractions of $\mathrm{OH}, \mathrm{CH}_{2} \mathrm{O}$, and $\mathrm{H}_{2} \mathrm{O}_{2}$ of autoignited laminar lifted methane/hydrogen jet flames with the modified $D_{\mathrm{H}_{2}}$. Contrary to the cases with the normal $D_{\mathrm{H}_{2}}, H_{\mathrm{L}}$ increases with increasing $U_{0}$, which clearly shows the effect of $D_{\mathrm{H}_{2}}$ on the liftoff characteristics of the lifted methane/hydrogen jet flames. Thus, it should be emphasized that the decreasing behavior of $H_{\mathrm{L}}$ is not due to chemical kinetics (or choice of kinetic mechanism as shown in Fig. 4) but due to physical aspects of differential diffusion.

To quantitatively compare the characteristics of the lifted jet flames with the normal and modified $D_{\mathrm{H}_{2}}$ under the LTHH condition, $\left(T_{\max }-T_{0}\right) / T_{\mathrm{ig}}$ together with $H_{\mathrm{L}}$ is shown in Fig. 11. While $H_{\mathrm{L}}$ show the opposite trends with increasing $U_{0}$ for the normal and modified $D_{\mathrm{H}_{2}}$ cases, both $\left(T_{\max }-T_{0}\right) / T_{\mathrm{ig}}$ values increase monotonically from the MILD combustion regime to the transition regime. Since the tribrachial edge flame regime is not observed for cases with the modified $D_{\mathrm{H}_{2}}$ due to the limitation of the present computational domain, we performed additional simulations with higher $U_{0}$ by extending the burner length to 100 $\mathrm{cm}$. From the results (not shown here), we found that both $H_{\mathrm{L}}$ and $\left(T_{\max }-T_{0}\right) / T_{\mathrm{ig}}$ values increase monotonically with $U_{0}$ and three different combustion regimes also exist for the modified $D_{\mathrm{H}_{2}}$ cases. 

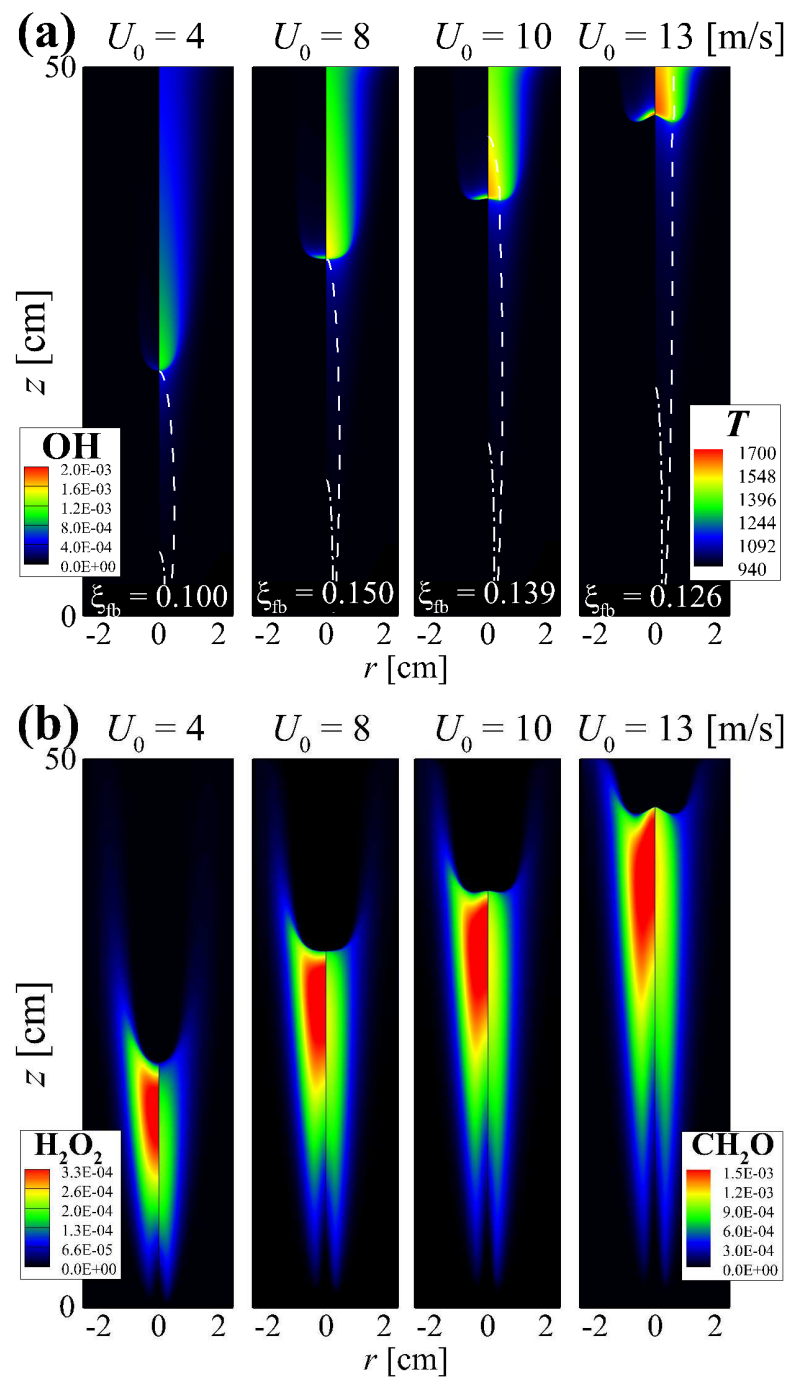

Figure 10: Isocontours of (a) $Y_{\mathrm{OH}}$ (left half) and $T$ (right half) and (b) $Y_{\mathrm{H}_{2} \mathrm{O}_{2}}$ (left half) and $Y_{\mathrm{CH}_{2} \mathrm{O}}$ (right half) for autoignited laminar lifted methane/hydrogen jet flames with modified $D_{\mathrm{H}_{2}}$ for various fuel jet velocities $U_{0}$ under the LTHH condition $\left(T_{0}=940 \mathrm{~K}\right.$ and $\left.R_{\mathrm{H}}=0.35\right)$. The dashed and dash-dotted lines in (a) represent the mixture fraction isoline passing through the flamebase, $\xi_{\mathrm{fb}}$, and the stoichiometric mixture fraction isoline, $\xi_{\mathrm{st}}(=0.378)$, respectively. 

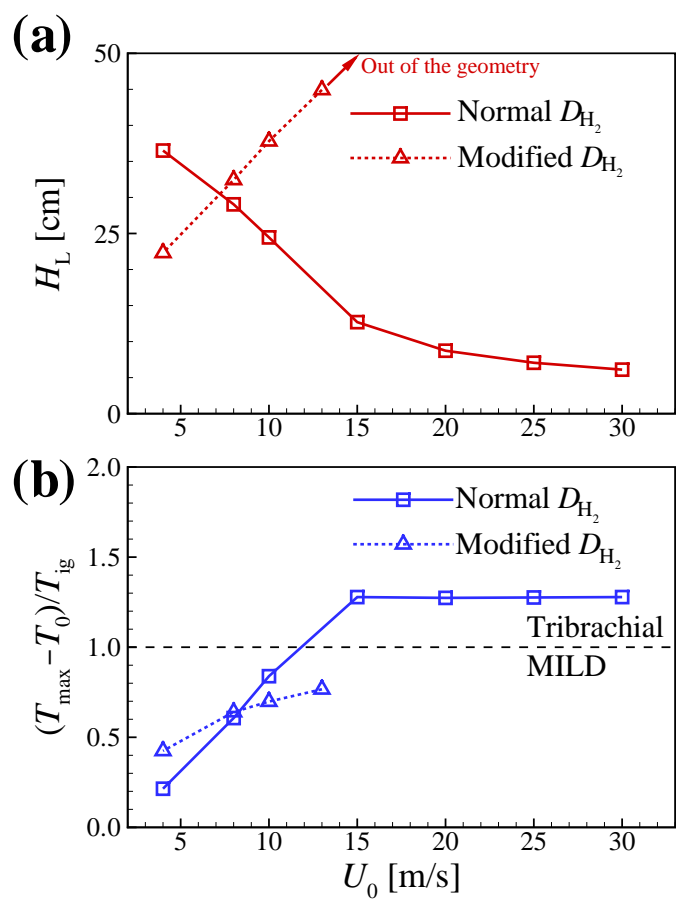

Figure 11: The variation of (a) $H_{\mathrm{L}}$ and (b) $\left(T_{\max }-T_{0}\right) / T_{\mathrm{ig}}$ for various fuel jet velocities with normal (solid line) and modified $H_{2}$ diffusivity (dashed line) under the LTHH condition $\left(T_{0}=940 \mathrm{~K}\right.$ and $\left.R_{\mathrm{H}}=0.35\right)$.

To further identify how large $D_{\mathrm{H}_{2}}$ affects the mixture conditions upstream of the flamebase and resultant ignition characteristics, we evaluate local hydrogen ratio, $R_{\mathrm{H}}$, along $\xi_{\mathrm{fb}}$ isoline for both normal and modified $D_{\mathrm{H}_{2}}$ cases. Here, $R_{\mathrm{H}}$ is evaluated based on the species information along $\xi_{\mathrm{fb}}$ isoline, for which all species are converted to the original reactants (i.e. $\mathrm{CH}_{4}, \mathrm{H}_{2}, \mathrm{O}_{2}$, and $\mathrm{N}_{2}$ ) by applying the element conservation law. Therefore, we can effectively estimate the differential diffusion effect through $R_{\mathrm{H}}$.

Figure 12 shows the profiles of $R_{\mathrm{H}}$ and $T$ along the $\xi_{\mathrm{fb}}$ isoline for cases with the normal and modified $D_{\mathrm{H}_{2}}$ at different $U_{0}$. It is readily observed that for normal $D_{\mathrm{H}_{2}}$, overall $R_{\mathrm{H}}$ increases with increasing $U_{0}$; it exhibits a much greater value than the original $R_{\mathrm{H}}$ value $(=0.35)$ of the fuel jet for relatively-large $U_{0}$ while it decreases and even vanishes near the flamebase for relatively-small $U_{0}$ cases. For modified $D_{\mathrm{H}_{2}}$, however, $R_{\mathrm{H}}$ value remains nearly the same regardless of $U_{0}$. In general, a hydrocarbon/air mixture with high $R_{\mathrm{H}}$ autoignites faster than that with low $R_{\mathrm{H}}[46,47]$, and as such, $R_{\mathrm{H}}$ profiles upstream of the flamebase for different $D_{\mathrm{H}_{2}}$ imply that for normal $D_{\mathrm{H}_{2}}$, the ignition of fuel jet can be 

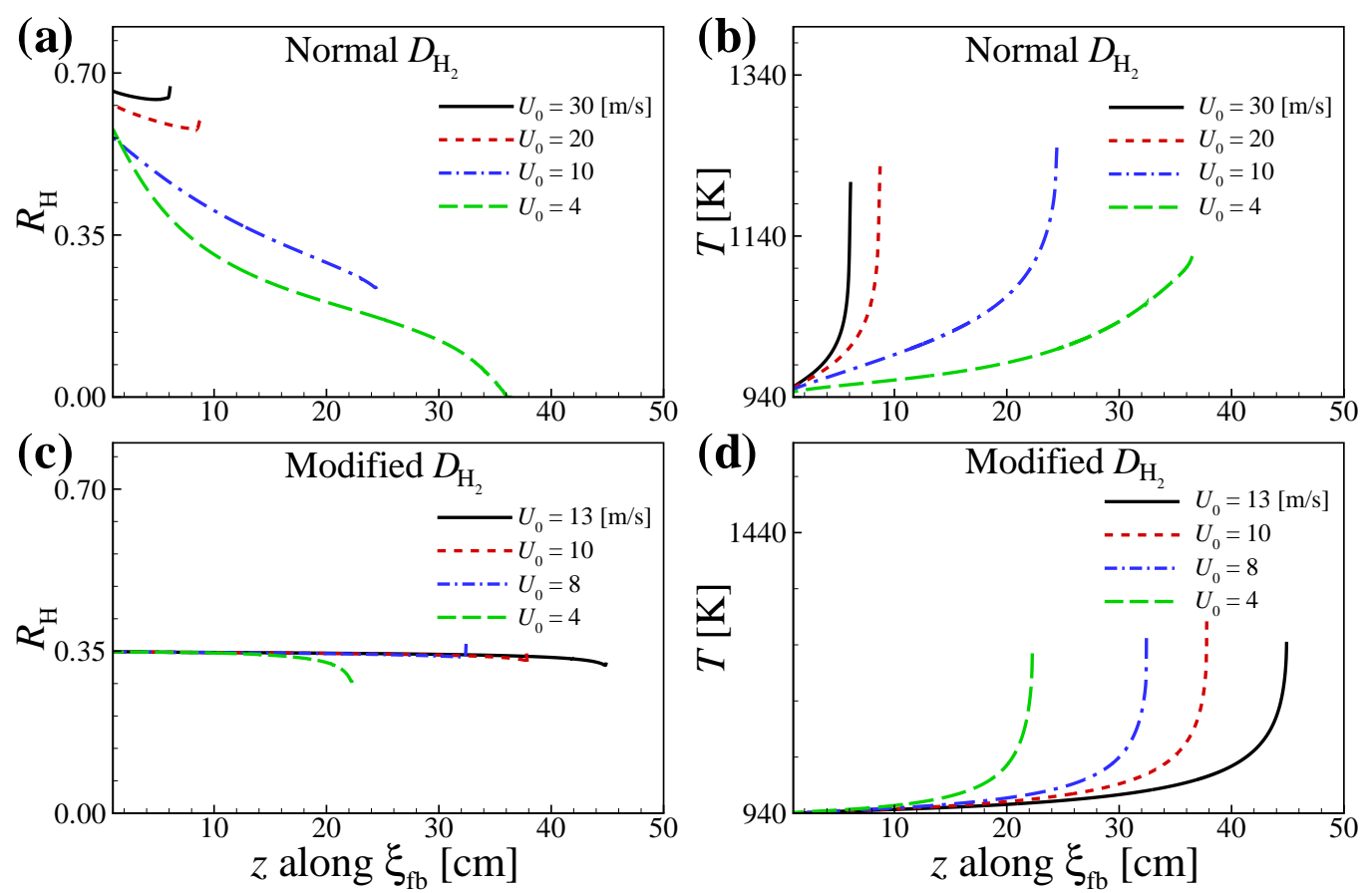

Figure 12: The profiles of $R_{\mathrm{H}}$ (left) and $T$ (right) along the mixture fraction isoline passing through the flamebase, $\xi_{\text {fb }}$, for various fuel jet velocities with normal (top) and modified (bottom) $\mathrm{H}_{2}$ diffusivities under the LTHH condition $\left(T_{0}=940 \mathrm{~K}\right.$ and $\left.R_{\mathrm{H}}=0.35\right)$.

enhanced with increasing $U_{0}$ while the effect of $U_{0}$ on the ignition of the fuel jet becomes negligible for modified $D_{\mathrm{H}_{2}}$. Consequently, the increase of local $T$ by ignition is enhanced with increasing $U_{0}$ for normal $D_{\mathrm{H}_{2}}$ (see Fig. $12 \mathrm{~b}$ ), whereas the profile of $T$ is just spatially elongated downstream with increasing $U_{0}$ for modified $D_{\mathrm{H}_{2}}$ (see Fig. 12d).

For heuristic argument purposes, a schematic of the $H_{\mathrm{L}}$ variation depending on $D_{\mathrm{H}_{2}}$ is shown in Fig. 13. For a given $U_{0}$ represented by the dash-dotted line, the axial velocity along $\xi_{\mathrm{fb}}$ isoline, $U$, is found to slightly increase due to local temperature increase by autoignition and/or the momentum diffusion of the fuel jet. However, the propagation speed of the leading edge of the lifted flame, $S_{\mathrm{e}}$, can significantly increase along $\xi_{\text {fb }}$ isoline due to local temperature increase by ongoing autoignition. As such, the lifted flame is stabilized at the flamebase where $S_{\mathrm{e}}$ balances local flow velocity represented by $U$ as illustrated in Fig. 13, which holds for both normal and modified $D_{\mathrm{H}_{2}}$ cases. However, $H_{\mathrm{L}}$ can exhibit different 
(a) Normal $D_{\mathrm{H}_{2}}$

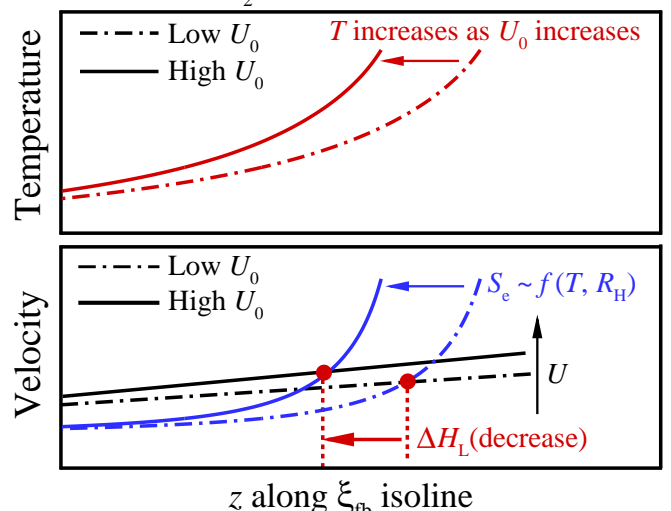

(b) Modified $D_{\mathrm{H}_{2}}$

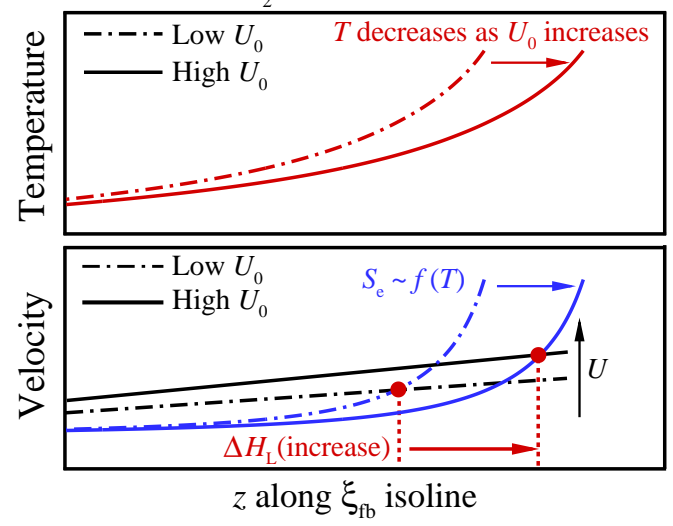

Figure 13: Schematic for the stabilization of autoignited laminar methane/hydrogen lifted flames with (a) normal and (b) modified $\mathrm{H}_{2}$ diffusivity.

behaviors depending on $D_{\mathrm{H}_{2}}$ when $U_{0}$ is increased.

For high $U_{0}$ with normal $D_{\mathrm{H}_{2}}$ represented by the solid line in Fig. 13a, even though overall $U$ along $\xi_{\mathrm{fb}}$ isoline increases compared to that of low $U_{0}$, overall temperature profile and resultant $S_{\mathrm{e}}$ move towards upstream compared to those of low $U_{0}$ due to spatiallyenhanced ignition process. Moreover, higher $R_{\mathrm{H}}$ contributes to further increase of $S_{\mathrm{e}}$ for high $U_{0}$. As such, the lifted flame with high $U_{0}$ is stabilized more upstream than that with low $U_{0}$ as described in Fig. 13a.

For modified $D_{\mathrm{H}_{2}}$ cases, however, the ignition characteristics do not change much for high $U_{0}$ such that the profiles of local temperature and resultant $S_{\mathrm{e}}$ are spatially elongated 
as shown in Figs. 12 and 13b. Therefore, the lifted flame with high $U_{0}$ is stabilized more downstream than that with low $U_{0}$ as illustrated in Fig. 13b. In summary, the increasing/decreasing $H_{\mathrm{L}}$ tendency for autoignited laminar lifted flames is primarily attributed to the ignition characteristics that affect local temperature and resultant $S_{\mathrm{e}}$ along the $\xi_{\mathrm{fb}}$ isoline.

\subsection{Effect of hydrogen on the lifted flame stabilization}

In this section, we elucidate how the high diffusive nature of hydrogen molecules affects the stabilization of the autoignited laminar lifted methane/hydrogen flames. First, we perform the transport budget analysis along the mixture fraction isoline passing through the flamebase, $\xi_{\mathrm{fb}}$, as in previous studies [48-50]. In the present study, hydroxyl $(\mathrm{OH})$ is adopted for the budget analysis since it is often used as a flame marker $[13,14,51]$. In a steady state, the convection $(\mathbf{C})$, diffusion $(\mathbf{D})$, and chemical reaction $(\mathbf{R})$ terms in the transport equation of a species balance one another. To take into account the two-dimensional diffusion process of the present simulations, $\mathbf{D}$ is decomposed into parallel $\mathbf{D}_{\mathbf{x}}$ and perpendicular $\mathbf{D}_{\mathbf{y}}$ to the $\xi_{\text {fb }}$ isoline, which are due to flame back diffusion and transverse stratification, respectively $[50,52]$. In the reaction zone of a typical premixed flame, $\mathbf{R}$ mainly balances $\mathbf{D}_{\mathbf{x}}$ while $\mathbf{C}$ is negligible. In an inhomogeneous autoignition process, however, $\mathbf{R}$ balances $\mathbf{C}$ and $\mathbf{D}_{\mathbf{y}}$ with negligible $\mathbf{D}_{\mathbf{x}}$.

Figure 14 shows the profiles of $\mathbf{C}, \mathbf{D}_{\mathbf{x}}, \mathbf{D}_{\mathbf{y}}$, and $\mathbf{R}$ along the $\xi_{\mathrm{fb}}$ isoline for $U_{0}=4,10$, and $30 \mathrm{~m} / \mathrm{s}$ under the LTHH condition, each of which represents the MILD combustion, transition, and tribrachial edge flame regimes, respectively. For $U_{0}=4 \mathrm{~m} / \mathrm{s}$ case, $\mathbf{R}$ mainly balances $\mathbf{C}$ and $\mathbf{D}_{\mathbf{y}}$ while $\mathbf{D}_{\mathbf{x}}$ is negligible, which indicates that the lifted flame with $U_{0}=4$ $\mathrm{m} / \mathrm{s}$ in the MILD combustion regime is primarily stabilized by inhomogeneous autoignition. For $U_{0}=10$ and $30 \mathrm{~m} / \mathrm{s}$ cases, the contribution of $\mathbf{D}_{\mathbf{x}}$ to the transport budget increases compared to that of $U_{0}=4 \mathrm{~m} / \mathrm{s}$, suggesting that the effect of flame propagation on the flame stabilization is no longer negligible. These results imply that the lifted flames with high $U_{0}$ would be stabilized by the effects of both autoignition and flame propagation, or autoignition-assisted flame propagation as discussed in [50, 53-55]. 


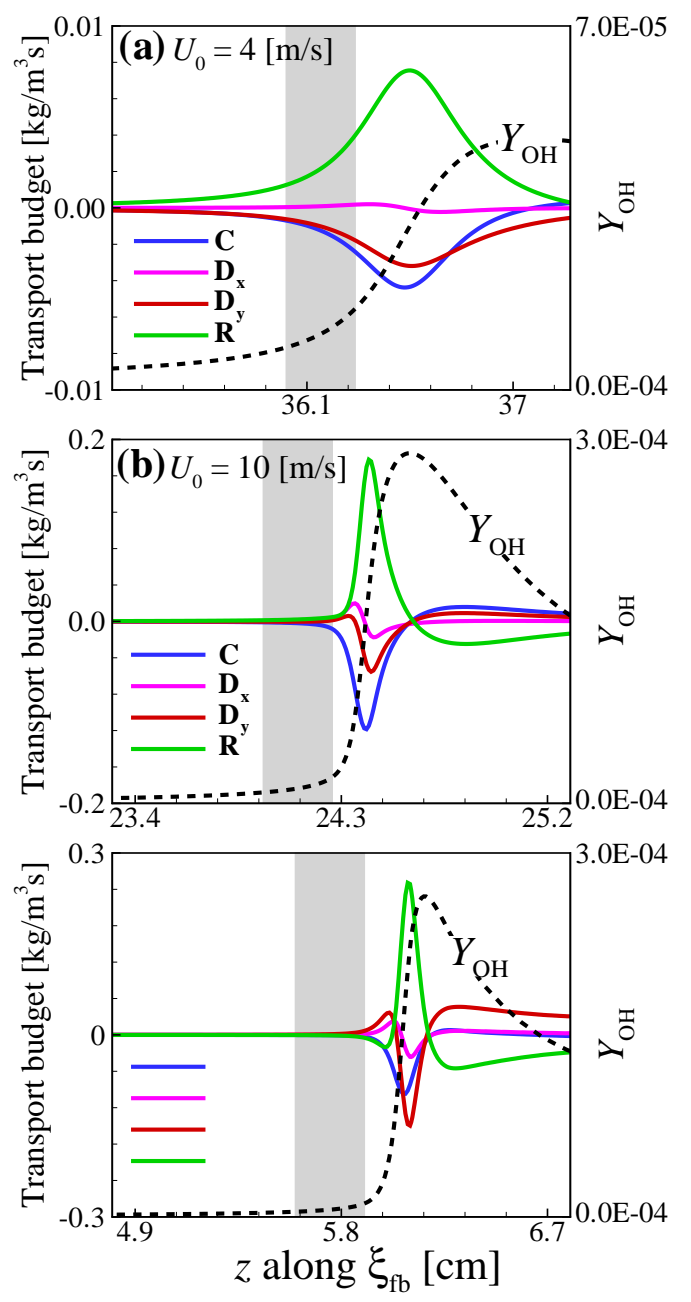

Figure 14: Profiles of convection (blue), diffusion in parallel (pink) and normal (red) direction, and chemical reaction (green) terms along the mixture fraction isoline passing through the flamebase, $\xi_{\mathrm{fb}}$, for (a) $U_{0}=4$, (b) 10 , and (c) $30 \mathrm{~m} / \mathrm{s}$. 
In addition to the species transport budget analysis, we also perform autoignition index, $A I$, analysis to further identify the stabilization mechanism of the autoignited laminar lifted methane/hydrogen jet flames. Schulz et al. [56] proposed $A I$ as a criterion to distinguish autoignition and flame propagation of a lifted methane/air jet flame. $A I$ was derived based on observation that the dominant $\mathrm{HO}_{2}$ consumption reaction changes depending on the stabilization mechanism; $\mathrm{HO}_{2}+\mathrm{H} \rightarrow \mathrm{OH}+\mathrm{OH}(\mathrm{R} 10)$ becomes predominant for the flame propagation mode and $\mathrm{HO}_{2}+\mathrm{OH} \rightarrow \mathrm{H}_{2} \mathrm{O}+\mathrm{O}_{2}$ (R14-15) overwhelms $\mathrm{R} 10$ for the autoignition mode. $A I$ is, therefore, defined as:

$$
A I=\left|\frac{\dot{\omega}_{\mathrm{HO}}^{(\mathrm{R} 14-15)}}{\dot{\omega}_{\mathrm{HO}_{2}}^{(\mathrm{R} 14-15)}+\dot{\omega}_{\mathrm{HO}_{2}}^{(\mathrm{R} 10)}}\right|,
$$

where $\dot{\omega}_{\mathrm{HO}_{2}}$ represent $\mathrm{HO}_{2}$ consumption rate. As such, a higher/lower $A I$ value implies that a lifted jet flame is primarily stabilized by autoignition/flame propagation. Figure 15 shows the profiles of $A I$ along the $\xi_{\text {fb }}$ isoline for cases with $U_{0}=4,10$, and $30 \mathrm{~m} / \mathrm{s}$ under the LTHH condition. For $U_{0}=30 \mathrm{~m} / \mathrm{s}$ case that represents a tribrachial edge flame, R10 and R14-15 balance each other at the flamebase and thus $A I \approx 0.5$. As $U_{0}$ decreases, the relative contribution of R14-15 to the overall $\dot{\omega}_{\mathrm{HO}_{2}}$ increases, leading to the increase of $A I$. These results also verify that autoignition-assisted flame propagation (or transition from flame propagation to autoignition) is the main stabilization mechanism for the lifted jet flames and the effect of autoignition increases with decreasing $U_{0}$.

Both the transport budget and autoignition index analyses can identify flame propagation or autoignition mode of a lifted jet flame but they may not be suitable for distinguishing autoignition-assisted flame propagation and autoignition. For instance, although $A I \approx 0.5$ and $\mathbf{C}-\mathbf{D}-\mathbf{R}$ balance imply the autoignition-assisted flame propagation, there still exists uncertainty about a threshold value to discern autoignition and autoignition-assisted flame propagation modes. When a lifted jet flame is stabilized either by autoignition or autoignition-assisted flame propagation, the degree of temperature increase and intermediate species build-up upstream of its flamebase can significantly vary depending on the flow condition as shown Fig. 7. This implies that the propagation speed of the flamebase of a 

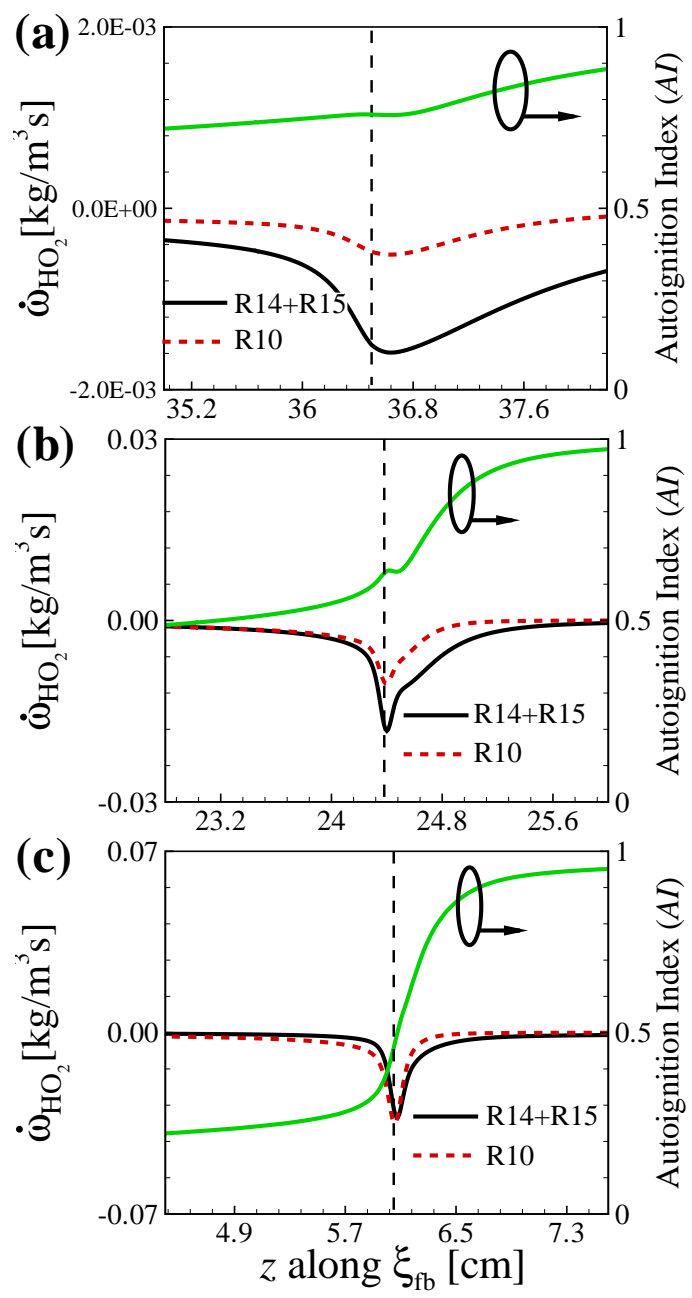

Figure 15: Profiles of R14-15 (black) and R10 (red) with autoignition index (green) along the mixture fraction isoline passing through the flamebase, $\xi_{\mathrm{fb}}$, for (a) $U_{0}=4$, (b) 10 , and (c) $30 \mathrm{~m} / \mathrm{s}$. The vertical dashed lines represent the flamebase location. 
lifted flame, $S_{\mathrm{e}}$, becomes comparable to/significantly greater than corresponding laminar flame speed, $S_{\mathrm{L}}$, if the lifted flame is stabilized by autoignition-assisted flame propagation/autoignition mode $[53,55,57]$.

To further identify the stabilization mechanism of the lifted flames, therefore, we evaluate $S_{\mathrm{e}}$ for various $U_{0}$ under the LTHH condition and then compare $S_{\mathrm{e}}$ with corresponding $S_{\mathrm{L}}$. Here, $S_{\mathrm{L}}$ is evaluated based on temperature and species information upstream of the flamebase to incorporate the effect of autoignition. For this purpose, $S_{\mathrm{e}}$ is obtained through the density-weight displacement speed, $S_{\mathrm{d}}^{*}$, which has been used to evaluate the propagation speed of reaction fronts in many previous studies $[13,14,58-64] . S_{\mathrm{d}}^{*}$ is defined by:

$$
S_{\mathrm{d}}^{*}=\frac{1}{\rho_{u}\left|\nabla Y_{k}\right|}\left(\omega_{k}-\frac{\partial}{\partial x_{j}}\left(\rho Y_{k} V_{j, k}\right)\right)
$$

where $Y_{k}$ is the mass fraction, $V_{j, k}$ the diffusion velocity in the $j$-direction, $\omega_{k}$ the net production rate of species $k$, and $\rho_{u}$ is the density of the unburnt mixture. $S_{\mathrm{d}}^{*}$ is evaluated at the most upstream point of $Y_{\mathrm{OH}}=2.3 \times 10^{-4}$ isoline defined as the flamebase.

In the present study, $S_{\mathrm{L}}$ upstream of the flamebase is estimated from transient 1-D reactive simulations as in $[6,48,62]$. The initial mixture conditions for the 1-D simulations were obtained from those at several locations upstream of the flamebase along the $\xi_{\mathrm{fb}}$ isoline as highlighted in grey in Fig. 14. The simulations were then initialized with a high-temperature ignition source such that a combustion wave develops from the source and propagates into the initial reactive mixture ahead of it. The reactive mixture upstream of the combustion wave does not autoignite until $\tau_{\mathrm{ig}}^{0}$, and hence, the propagation speed of the combustion wave, $S_{\mathrm{d}}^{*}$, can be considered as the laminar burning velocity, $S_{\mathrm{L}}$, similar to the diffusive limit found in previous studies $[6,48,62]$. Note that in the present study, it is not straightforward to precisely determine $S_{\mathrm{L}}$ values because autoignition process is underway producing heat and radicals. To reasonably estimate $S_{\mathrm{L}}$, therefore, we evaluate it based on the local mixture components and temperature upstream of the flamebase, for which species components are converted to the original reactants at the inlets (i.e. $\mathrm{CH}_{4}, \mathrm{H}_{2}, \mathrm{O}_{2}$, and $\mathrm{N}_{2}$ ) as for $R_{\mathrm{H}}$ calculation. Then, we evaluate $S_{\mathrm{L}}$ of the unburned mixture at the local temperature. Although this method cannot evaluate $S_{\mathrm{L}}$ perfectly, it can provide rough estimate of $S_{\mathrm{L}}$ values. 
Figure 16 shows $S_{\mathrm{L}}$ and $S_{\mathrm{e}} / S_{\mathrm{L}}$ at several locations along the $\xi_{\mathrm{fb}}$ isoline upstream of the flamebase for $U_{0}=4,10$, and $30 \mathrm{~m} / \mathrm{s}$ under the LTHH condition. Note that $S_{\mathrm{e}}$ at the flamebase is found to be $1.45,1.81$, and $1.25 \mathrm{~m} / \mathrm{s}$ for $U_{0}=4,10$, and $30 \mathrm{~m} / \mathrm{s}$, respectively. As mentioned above, $U_{0}=4,10$, and $30 \mathrm{~m} / \mathrm{s}$ cases represent the MILD combustion, transition, and tribrachial edge flame regimes, respectively. Two points are to be noted. First, it is readily observed that $S_{\mathrm{L}}$ increases as the $S_{\mathrm{L}}$ measuring point approaches the flamebase, which verifies that $S_{\mathrm{e}}$ can increase along the $\xi_{\mathrm{fb}}$ isoline upstream of the flamebase as illustrated in Fig. 13. Second, it is also observed that for $U_{0}=10$ and $30 \mathrm{~m} / \mathrm{s}$ cases, $S_{\mathrm{e}} / S_{\mathrm{L}}$ is close to unity even though the former/latter is slightly larger/smaller than unity, which implies that the autoignited lifted jet flames of the transition and tribrachial edge flame regimes can be stabilized by the flame propagation mode. For these cases, however, $S_{\mathrm{e}}$ is considerably greater than the corresponding laminar burning velocity under non-autoignitive conditions or low-temperature conditions such that the lifted jet flames are stabilized by the autoignitionassisted flame propagation mode for which the edge flame speed of the lifted jet flames is significantly enhanced by temperature increase induced by autoignition upstream of the flamebase. For $U_{0}=4 \mathrm{~m} / \mathrm{s}$ case, however, $S_{\mathrm{e}} / S_{\mathrm{L}}$ is an order of magnitude greater than unity, which indicates that the lifted jet flames with relatively-low $U_{0}$ are primarily stabilized by autoignition. These results are consistent with those of species transport budget and autoignition index analyses.

It is of interest to note that the stabilization mechanism of the present autoignited lifted methane/hydrogen jet flames seems to be contrary to those of previous studies $[50,52,53]$ : the role of flame propagation on the flame stabilization enhances/mitigates with increasing $U_{0}$ for the present/previous studies. As discussed above, we can determine the stabilization mechanism of a lifted flame based on the relative magnitude of the propagation speed of the flamebase, $S_{\mathrm{e}}$, to the laminar burning velocity of a mixture upstream of the flamebase, $S_{\mathrm{L}}$ : i.e., a lifted flame is stabilized by flame propagation/autoignition when $S_{\mathrm{e}}$ is comparable to/signficantly greater than $S_{\mathrm{L}}$. In previous studies $[50,52,53]$, single component fuels (i.e., DME, $n$-heptane, and ethanol) were used such that $S_{\mathrm{L}}$ of a lifted flame does not change with 

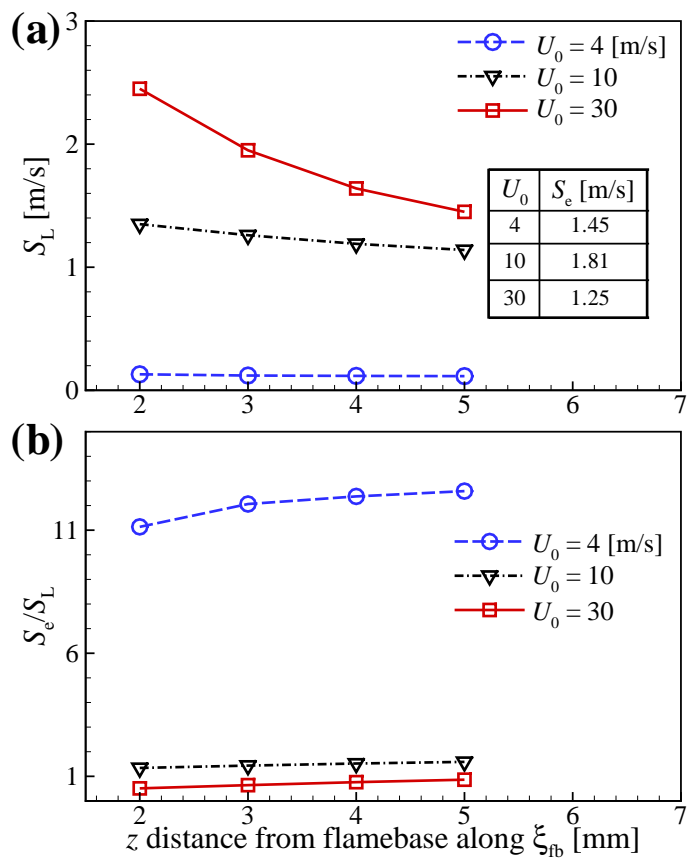

Figure 16: Variation of (a) $S_{\mathrm{L}}$ and (b) $S_{\mathrm{e}} / S_{\mathrm{L}}$ at 2, 3, 4, and $5 \mathrm{~mm}$ upstream of the flamebase along the mixture fraction isoline passing through the flamebase, $\xi_{\mathrm{fb}}$, for $U_{0}=4,10$, and $30 \mathrm{~m} / \mathrm{s}$ cases.

$U_{0}$. At relatively-low $U_{0}$, therefore, a lifted flame can be stabilized by flame propagation because $S_{\mathrm{e}}\left(\sim S_{\mathrm{L}}\right)$ can balance relatively-low local flow velocity, $U: S_{\mathrm{L}} \sim S_{\mathrm{e}}=U$. However, a lifted flame can be stabilized by autoignition at relatively-high $U_{0}$ where only high $S_{\mathrm{e}}$ induced by autoignition can balance local flow velocity that is way high compared to $S_{\mathrm{L}}$ : $S_{\mathrm{e}}=U \gg S_{\mathrm{L}}$

However, in the present study we adopted a binary component fuel of $\mathrm{CH}_{4}$ and $\mathrm{H}_{2}$ highly diluted by $\mathrm{N}_{2}$ (i.e., $X_{\mathrm{F}, 0}=0.2$ ), for which the diffusion coefficients are significantly different between them. The laminar burning velocity and ignition delay of such binary fuel significantly vary depending on its compositions, and as such, $S_{\mathrm{L}}$ of a lifted flame changes significantly with $U_{0}$ due to the differential diffusion effect (see Fig. 16a). At relatively-high $U_{0}$, large $R_{\mathrm{H}}$ at the flamebase enhances $S_{\mathrm{L}}$ such that a lifted flame can be stabilized by flame propagation, which is actually autoignition-assisted flame propagation as discussed above: $S_{\mathrm{L}} \sim S_{\mathrm{e}}=U$. At relatively-low $U_{0}$, however, $R_{\mathrm{H}}$ nearly vanishes and the entire jet becomes very lean near the flamebase such that $S_{\mathrm{L}}$ exhibits much lower value than local flow velocity: 
$S_{\mathrm{L}} \ll U$. Then, a lifted flame with low $U_{0}$ can be stabilized only by autoignition for which relatively-high $S_{\mathrm{e}}$ induced by autoignition can balance local flow velocity: $S_{\mathrm{e}}=U \gg S_{\mathrm{L}}$.

\section{Ignition characteristics: CEMA}

To further elucidate the spatial ignition and flame stabilization characteristics of the lifted flames, we perform chemical explosive mode analysis (CEMA). CEMA has been successfully adopted to systematically identify key species and reactions for premixed/non-premixed flames and ignition/extinction processes in laminar/turbulent lifted jet flames in heated coflows [14, 42, 43, 52, 65], turbulent reacting jet flames in cross flows [66, 67], and ignition of hydrocarbon fuel/air mixtures under HCCI conditions [8, 44, 45, 68].

As mentioned above, the Jacobian of the chemical source term of the discretized conservation equations for a chemically-reacting system has the chemical information of local mixtures, and hence, we can determine their chemical characteristics using the Jacobian [42-44]. To identify the chemical feature in CEMA, a chemical mode is defined as an eigenmode of the Jacobian, which is associated with an eigenvalue, $\lambda_{e}$, and a corresponding pair of the left and right eigenvectors, $\mathbf{a}_{e}$ and $\mathbf{b}_{e}$. Chemical explosive mode (CEM) is a chemical mode for which the real part of eigenvalue is positive, $\operatorname{Re}\left(\lambda_{e}\right)>0$. From CEMA, the critical chemical kinetic processes occurring in the autoignited laminar lifted flames can be identified by evaluating explosive index (EI) and participation index (PI) of local mixtures. EI and PI are defined as [43-45]:

$$
\begin{gathered}
\mathbf{E I}=\frac{\left|\mathbf{a}_{e} \otimes \mathbf{b}_{e}^{T}\right|}{\sum\left|\mathbf{a}_{e} \otimes \mathbf{b}_{e}^{T}\right|}, \\
\mathbf{P I}=\frac{\left|\left(\mathbf{b}_{e} \cdot \mathbf{S}\right) \otimes \mathbf{R}\right|}{\sum\left|\left(\mathbf{b}_{e} \cdot \mathbf{S}\right) \otimes \mathbf{R}\right|},
\end{gathered}
$$

where $\mathbf{S}$ and $\mathbf{R}$ represent the stoichiometric coefficient matrix and the vector of the net rates for reactions, respectively. The symbol $\otimes$ denotes the element-wise multiplication of two vectors. EI and PI indicate the normalized contribution of each variable and reaction to a CEM, respectively, and as such, key species and reactions to ignition near the flamebase can be elucidated by evaluating EI and PI values. 
Figure 17 shows the EI isocontours of several important variables for the lifted flames in three different regimes (i.e. $U_{0}=4,10$, and $30 \mathrm{~m} / \mathrm{s}$ ) under the LTHH condition. Heat release rate is also presented in the figure to show the flame location. Two points are to be noted from the figure. First, for all regimes the most important EI variable upstream of the flamebase is temperature while $\mathrm{CH}_{4}, \mathrm{CH}_{2} \mathrm{O}, \mathrm{H}_{2} \mathrm{O}_{2}$ and $\mathrm{H}_{2}$ also contribute to the CEM upstream of the flamebase, showing a general sequence of autoignition of methane/air or hydrogen/air mixture [2]. Second, for the MILD combustion regime $\left(U_{0}=4 \mathrm{~m} / \mathrm{s}\right)$ the contribution of $\mathrm{CH}_{4}$ to the CEM becomes significant right upstream of the flamebase. For the tribrachial edge flame regime $\left(U_{0}=30 \mathrm{~m} / \mathrm{s}\right)$, however, the contribution of $\mathrm{H}_{2}$ to the CEM becomes important. These results substantiate that hydrogen molecules with large mass diffusivity play a critical role in stabilizing the lifted flame in the tribrachial edge flame regime while the ignition of methane is critical to the MILD combustion.

To further identify the chemical characteristics of the lifted flames in different regimes, the contribution of each chemical reaction to the CEM, or the PI isocontours of important reactions are shown in Fig. 18. Although the chemical features of the lifted flames have been briefly investigated through the EI analysis, we can further examine which reaction affects the CEM through the PI analysis. For the MILD combustion regime $\left(U_{0}=4 \mathrm{~m} / \mathrm{s}\right)$, we can readily observe a general sequence of autoignition of methane/air mixture upstream of the flamebase [2]: after the $\mathrm{H}$ abstraction from $\mathrm{CH}_{4}$ near the fuel nozzle (not shown), the conversion of $\mathrm{CH}_{3}$ to $\mathrm{CH}_{3} \mathrm{O} / \mathrm{CH}_{2} \mathrm{O}$ to $\mathrm{HCO}$ occurs in sequence through $\mathrm{CH}_{3}+\left(\mathrm{O}, \mathrm{O}_{2}\right.$, $\left.\mathrm{HO}_{2}, \mathrm{O}_{2}\right) \rightarrow\left(\mathrm{CH}_{2} \mathrm{O}+\mathrm{H}, \mathrm{CH}_{2} \mathrm{O}+\mathrm{OH}, \mathrm{CH}_{3} \mathrm{O}+\mathrm{OH}, \mathrm{CH}_{3} \mathrm{O}+\mathrm{O}\right)(\mathrm{R} 49, \mathrm{R} 51-53), \mathrm{CH}_{3} \mathrm{O}$ $+\left(\mathrm{O}_{2}, \mathrm{M}\right) \rightarrow \mathrm{CH}_{2} \mathrm{O}+\left(\mathrm{HO}_{2}, \mathrm{H}+\mathrm{M}\right)(\mathrm{R} 78, \mathrm{R} 79)$, and $\mathrm{CH}_{2} \mathrm{O}+\left(\mathrm{H}, \mathrm{O}, \mathrm{OH}, \mathrm{HO}_{2}\right) \rightarrow \mathrm{HCO}$ $+\left(\mathrm{H}_{2}, \mathrm{OH}, \mathrm{H}_{2} \mathrm{O}, \mathrm{H}_{2} \mathrm{O}_{2}\right)(\mathrm{R} 36-38, \mathrm{R} 40)$ as shown in Figs. 18a and b. In addition, $\mathrm{H}_{2} \mathrm{O}_{2}$ $+\mathrm{M} \rightarrow \mathrm{OH}+\mathrm{OH}+\mathrm{M}(-\mathrm{R} 16)$ occurs more actively as a part of radical growth for the methane oxidation (see Fig. 18c). The final $\mathrm{CO}$ conversion to $\mathrm{CO}_{2}$ occurs as the main heat release step right after the conversion of $\mathrm{HCO}$ to $\mathrm{CO}$ occurring just upstream of the flame (not shown). 

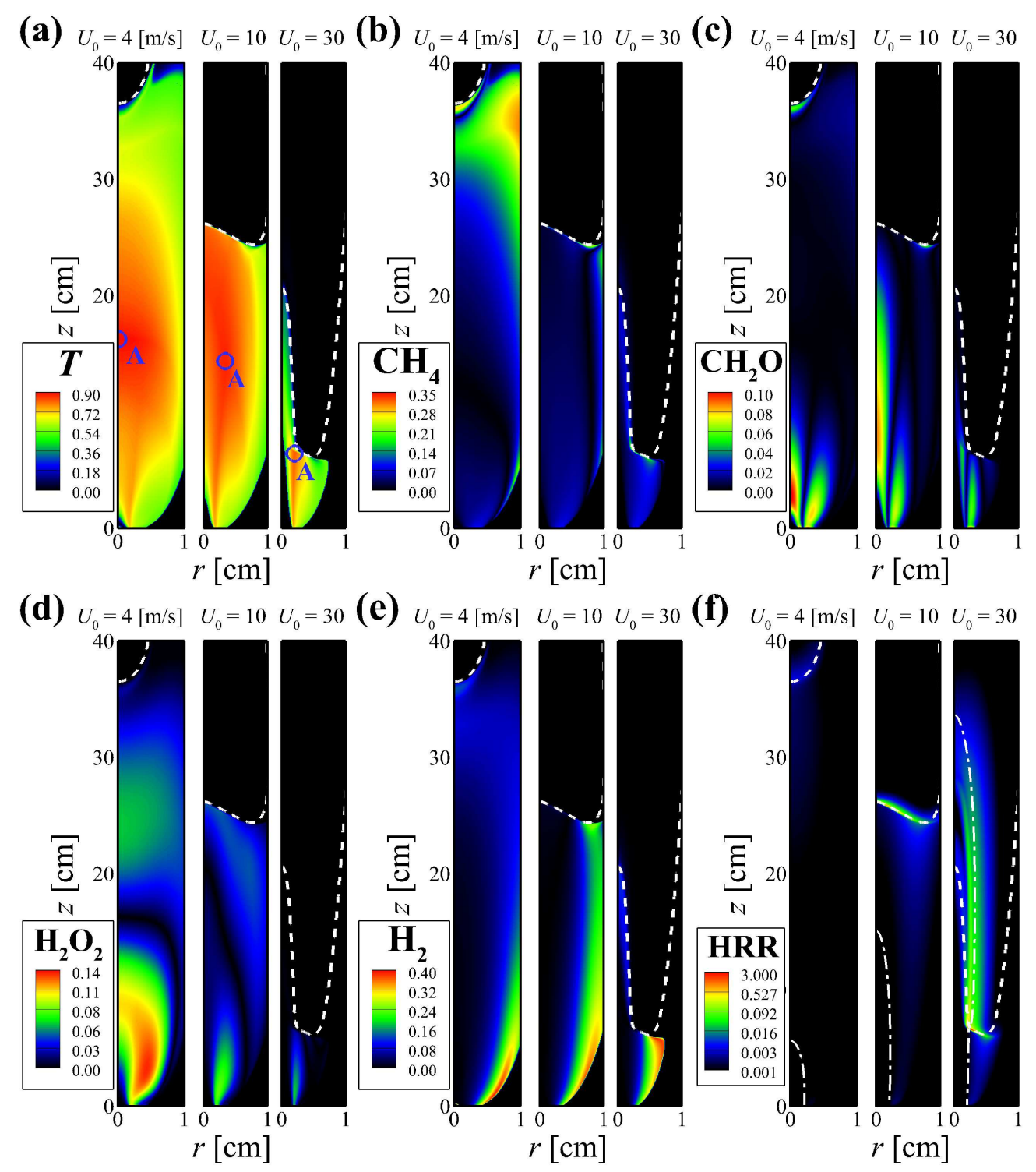

Figure 17: Isocontours of EI of (a) T, (b) $\mathrm{CH}_{4}$, (c) $\mathrm{CH}_{2} \mathrm{O}$, (d) $\mathrm{H}_{2} \mathrm{O}_{2}$, and (e) $\mathrm{H}_{2}$, and (f) heat release rate $\left(\mathrm{J} / \mathrm{mm}^{3} \mathrm{~s}\right)$ for autoignited laminar lifted methane/hydrogen jet flames with $U_{0}=4,10$, and $30 \mathrm{~m} / \mathrm{s}$ under the LTHH condition. The dashed line represents an isoline of $\operatorname{Re}\left(\lambda_{\mathrm{e}}\right)=0$ and the dash-dotted in (f) denotes the stoichiometric mixture fraction isoline, $\xi_{\mathrm{st}}$. 

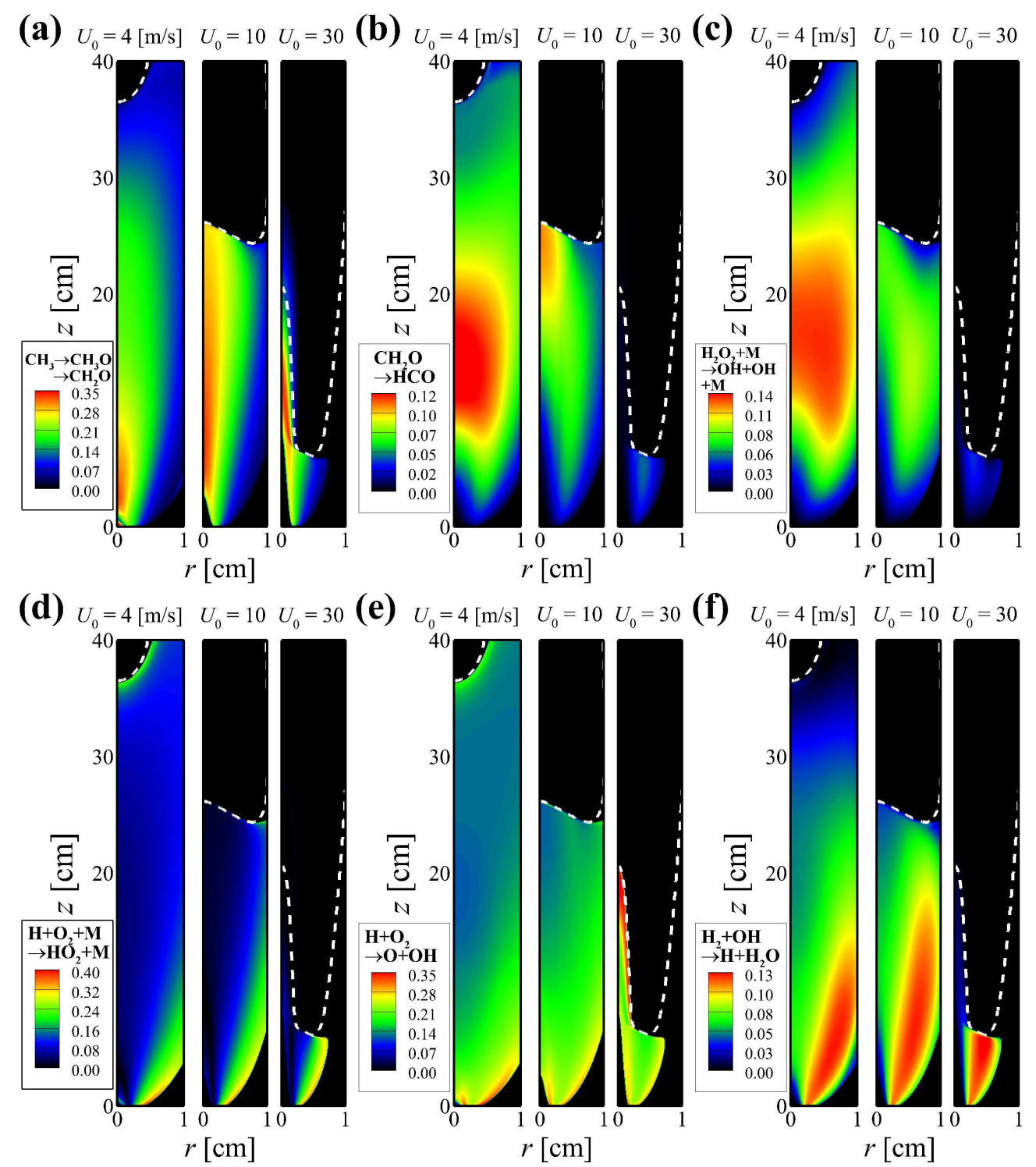

Figure 18: Isocontours of PI of (a) reactions of $\mathrm{CH}_{3}$ conversion to $\mathrm{CH}_{2} \mathrm{O}$ and $\mathrm{CH}_{3} \mathrm{O}$, (b) $\mathrm{CH}_{2} \mathrm{O}$ conversion to $\mathrm{HCO}$, (c) $\mathrm{H}_{2} \mathrm{O}_{2}+\mathrm{M} \rightarrow \mathrm{OH}+\mathrm{OH}+\mathrm{M}(-\mathrm{R} 16)$, (d) $\mathrm{H}+\mathrm{O}_{2}+\mathrm{M} \rightarrow \mathrm{HO}_{2}+\mathrm{M}$ (R9), (e) $\mathrm{H}+\mathrm{O}_{2} \rightarrow \mathrm{O}+$ $\mathrm{OH}$ (R1), and (f) $\mathrm{H}_{2}+\mathrm{OH} \rightarrow \mathrm{H}+\mathrm{H}_{2} \mathrm{O}$ (R3) for autoignited laminar lifted methane/hydrogen jet flames for cases with $U_{0}=4,10$, and $30 \mathrm{~m} / \mathrm{s}$. The dashed line represents an isoline of $\operatorname{Re}\left(\lambda_{\mathrm{e}}\right)=0$. 
For the tribrachial edge flame regime $\left(U_{0}=30 \mathrm{~m} / \mathrm{s}\right)$, however, we can identify from Figs. $18 \mathrm{~d}-\mathrm{f}$ that the contribution of hydrogen oxidation reactions to the CEM becomes significant upstream of the flamebase: the recombination reaction of $\mathrm{H}+\mathrm{O}_{2}+\mathrm{M} \rightarrow \mathrm{HO}_{2}$ $+\mathrm{M}(\mathrm{R} 9)$ competes with the chain branching reaction of $\mathrm{H}+\mathrm{O}_{2} \rightarrow \mathrm{O}+\mathrm{OH}(\mathrm{R} 1)$ far upstream of the flamebase; however, the latter becomes more important than the former as it comes to the flamebase; especially, the contribution of the chain branching reaction (R1) and the hydrogen heat release reaction of $\mathrm{H}_{2}+\mathrm{OH} \rightarrow \mathrm{H}+\mathrm{H}_{2} \mathrm{O}$ (R3) become dominant right upstream of the flamebase. In summary, the PI analysis identifies the occurrence of distinct methane and hydrogen oxidation processes upstream of the flamebases for different regimes, which clearly shows that the hydrogen effect on the unusual decreasing $H_{\mathrm{L}}$ behavior with increasing $U_{0}$ is due to the hydrogen chemistry, which is originally from the fast diffusion of hydrogen molecules from the fuel jet.

To quantitatively identify the ignition characteristics of the lifted flames, PI values of important reactions at Point A, delineated in Fig. 17a, are shown in Fig. 19. Point A indicates a location where thermal ignition process attains its peak (i.e. the maximum $\mathrm{EI}(T)$ point in the domain). By comparing PI values of important reactions at this point, we identify the relative contribution of methane and hydrogen oxidation to the CEM in the different regimes. It is readily observed from PI values at Point $\mathrm{A}$ that the contribution of the methane oxidation to the CEM represented by the conversion of $\mathrm{CH}_{2} \mathrm{O}$ to $\mathrm{HCO}$ ( $\mathrm{R} 36-38$ and R40) or radical growth (-R16) becomes large for the MILD combustion regime $\left(U_{0}=4\right.$ $\mathrm{m} / \mathrm{s})$.

However, the overall contribution of the hydrogen oxidation to the CEM increases with increasing $U_{0}$; the chain branching reaction of hydrogen oxidation (R1) dominates over the recombination reactions (R9) for all $U_{0}$ cases and the difference between $\mathrm{R} 1$ and $\mathrm{R} 9$ becomes more significant for cases with large $U_{0}$. A similar trend is also observed for the heat release reaction of hydrogen (R3) at Point A. These results imply that the hydrogen oxidation chemistry is more enhanced upstream of the lifted jet flames with increasing $U_{0}$ due to higher $\mathrm{H}_{2}$ concentration caused by its fast diffusion, which leads to advancing the oxidation of the methane/hydrogen jet. In summary, the contribution of the hydrogen oxidation 


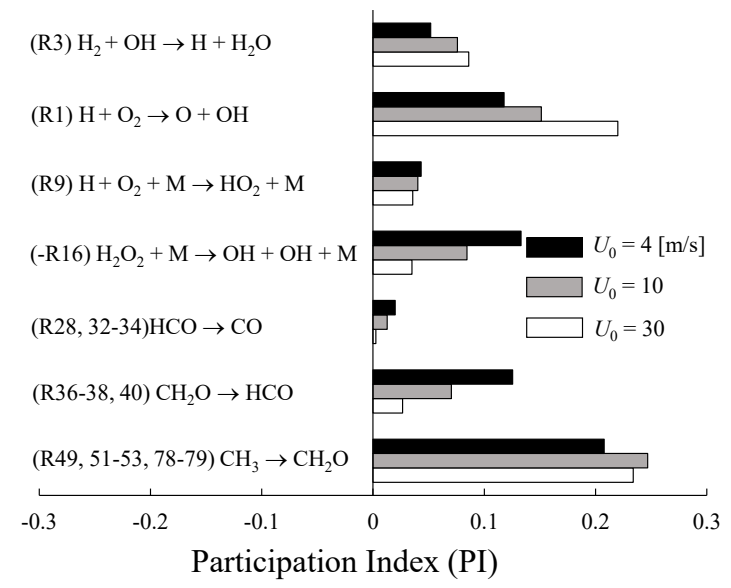

Figure 19: PIs of selected reactions at the sampled point, Point A. Location of Point A is specified in Fig. 17a

reactions to the CEM for the tribrachial edge flame regime is relatively larger than that for the MILD combustion regime, and as such, the oxidation of the fuel jet for the tribrachial edge flame regime occurs faster than that for the MILD combustion regime.

\section{Conclusions}

The characteristics of autoignited laminar lifted methane/hydrogen jet flames in heated coflow air were numerically investigated using laminarSMOKE code with a 57-species detailed chemical kinetic mechanism of methane oxidation. The detailed numerical simulations were performed for various fuel jet velocities under the HTLH and LTHH conditions. The numerical simulations captured qualitatively different lifted flame behaviors under the HTLH and LTHH conditions, in agreement with those in experiments. To identify the effect of differential diffusion on the unusual $H_{\mathrm{L}}$ behavior under the LTHH condition, additional numerical simulations with modified $D_{\mathrm{H}_{2}}$ were also carried out. The following results were obtained from the simulations together with the transport budget, autoignition index, displacement speed, and chemical explosive mode analyses.

1. Considering the flame structure and $\left(T_{\max }-T_{0}\right) / T_{\mathrm{ig}}$, we categorized the autoignited laminar lifted methane/hydrogen jet flames under the LTHH condition into three dif- 
ferent combustion regimes: the MILD combustion, transition, and tribrachial edge flame regimes.

2. From the simulations with normal and modified $D_{\mathrm{H}_{2}}$, it was verified that the high diffusive nature of hydrogen molecules or the differential diffusion between methane and hydrogen is primarily attributed to the unusual decreasing $H_{\mathrm{L}}$ behavior with increasing $U_{0}$ under the LTHH condition.

3. In the MILD combustion regime under the LTHH condition, local hydrogen ratio, $R_{\mathrm{H}}$, along the $\xi_{\mathrm{fb}}$ isoline decreases because hydrogen molecules in the fuel jet have enough time to diffuse out from the center, and hence, local temperature increase by autoignition is relatively reduced compared to that in the tribrachial edge flame regime. On the other hand, in the tribrachial edge flame regime, the flamebase locates radially outside and more hydrogen molecules can diffuse into the flamebase. Therefore, $R_{\mathrm{H}}$ along the $\xi_{\mathrm{fb}}$ isoline increases and local temperature increase by autoignition is relatively enhanced. Such $R_{\mathrm{H}}$ characteristics lead to the decrease of $H_{\mathrm{L}}$ with increasing $U_{0}$.

4. The species transport budget, autoignition index, and displacement speed analyses revealed that the stabilization of the autoignited lifted methane/hydrogen jet flames is affected by both autoignition and flame propagation. The role of flame propagation on their stabilization increases with increasing $U_{0}$ due to the $R_{\mathrm{H}}$ characteristics depending on $U_{0}$ and the flamebase locations: a lifted flame in the MILD combustion regime is primarily stabilized by autoignition while it in the tribrachial edge flame regime is stabilized by autoignition-assisted flame propagation.

5. The chemical explosive mode analysis identified the ignition process upstream of the flamebase and the difference between the tribrachial edge flame and MILD combustion regimes. In the tribrachial edge flame regime, the overall contribution of hydrogenrelated reactions to the CEM becomes greater than that in the MILD combustion regime. Therefore, local temperature increase is relatively enhanced upstream of the flamebase in the tribrachial edge flame regime, leading to the decrease of $H_{\mathrm{L}}$. 


\section{Acknowledgment}

This work was supported by Basic Science Research Program through the National Research Foundation of Korea (NRF) funded by the Ministry of Science and ICT (NRF2018R1A2A2A05018901). This research used the resources of the KAUST Supercomputing Laboratory and UNIST Supercomputing Center.

\section{References}

[1] N. Peters, Turbulent combustion, Cambridge University Press, 2000.

[2] C. K. Law, Combustion Physics, Cambridge University Press, 2006.

[3] J. E. Dec, Advanced compression-ignition engines-understanding the in-cylinder processes, Proc. Combust. Inst. 32 (2009) 2727-2742.

[4] S. Saxena, I. D. Bedoya, Fundamental phenomena affecting low temperature combustion and HCCI engines, high load limits and strategies for extending these limits, Prog. Energy Combust. Sci. 39 (2013) $457-488$.

[5] R. D. Reitz, G. Duraisamy, Review of high efficiency and clean reactivity controlled compression ignition (RCCI) combustion in internal combustion engines, Prog. Energy Combust. Sci. 46 (2015) 12-71.

[6] C. S. Yoo, T. Lu, J. H. Chen, C. K. Law, Direct numerical simulations of ignition of a lean n-heptane/air mixture with temperature inhomogeneities at constant volume: Parametric study, Combust. Flame 158 (2011) 1727-1741.

[7] C. S. Yoo, Z. Luo, T. Lu, H. Kim, J. H. Chen, A DNS study of ignition characteristics of a lean iso-octane/air mixture under HCCI and SACI conditions, Proc. Combust. Inst. 34 (2013) 2985-2993.

[8] M. B. Luong, T. Lu, S. H. Chung, C. S. Yoo, Direct numerical simulations of the ignition of a lean biodiesel/air mixture with temperature and composition inhomogeneities at high pressure and intermediate temperature, Combust. Flame 161 (2014) 2878-2889.

[9] M. B. Luong, G. H. Yu, T. Lu, S. H. Chung, C. S. Yoo, Direct numerical simulations of ignition of a lean n-heptane/air mixture with temperature and composition inhomogeneities relevant to HCCI and SCCI combustion, Combust. Flame 162 (2015) 4566-4585.

[10] M. B. Luong, G. H. Yu, S. H. Chung, C. S. Yoo, Ignition of a lean PRF/air mixture under RCCI/SCCI conditions: A comparative DNS study, Proc. Combust. Inst. 36 (2017) 3623-3631.

[11] M. B. Luong, R. Sankaran, G. H. Yu, S. H. Chung, C. S. Yoo, On the effect of injection timing on the ignition of lean PRF/air/EGR mixtures under direct dual fuel stratification conditions, Combust. Flame 183 (2017) 309-321. 
[12] L. M. Pickett, Low flame temperature limits for mixing-controlled Diesel combustion, Proc. Combust. Inst. 30 (2005) 2727-2735.

[13] C. S. Yoo, R. Sankaran, J. H. Chen, Three-dimensional direct numerical simulation of a turbulent lifted hydrogen jet flame in heated coflow: Flame stabilization and structure, J. Fluid Mech. 640 (2009) $453-481$.

[14] C. S. Yoo, E. S. Richardson, R. Sankaran, J. H. Chen, A DNS study on the stabilization mechanism of a turbulent lifted ethylene jet flame in highly-heated coflow, Proc. Combust. Inst. 33 (2011) 1619-1627.

[15] B. C. Choi, K. N. Kim, S. H. Chung, Autoignited laminar lifted flames of propane in coflow jets with tribrachial edge and mild combustion, Combust. Flame 156 (2009) 396-404.

[16] B. C. Choi, S. H. Chung, Autoignited laminar lifted flames of methane, ethylene, ethane, and n-butane jets in coflow air with elevated temperature, Combust. Flame 157 (2010) 2348-2356.

[17] B. C. Choi, S. H. Chung, Autoignited laminar lifted flames of methane/hydrogen mixtures in heated coflow air, Combust. Flame 159 (2012) 1481-1488.

[18] S. M. Al-Noman, S. K. Choi, S. H. Chung, Numerical study of laminar nonpremixed methane flames in coflow jets: Autoignited lifted flames with tribrachial edges and MILD combustion at elevated temperatures, Combust. Flame 171 (2016) 119-132.

[19] S. K. Choi, S. H. Chung, Autoignited and non-autoignited lifted flames of pre-vaporized n-heptane in coflow jets at elevated temperatures, Combust. Flame 160 (2013) 1717-1724.

[20] S. M. Al-Noman, S. K. Choi, S. H. Chung, Autoignition characteristics of laminar lifted jet flames of pre-vaporized iso-octane in heated coflow air, Fuel 162 (2015) 171-178.

[21] S. M. Al-Noman, B. C. Choi, S. H. Chung, Autoignited lifted flames of dimethyl ether in heated coflow air, Combust. Flame 195 (2018) 75-83.

[22] M. de Joannon, A. Saponaro, A. Cavaliere, Zero-dimensional analysis of methane diluted oxidation in rich conditions, Proc. Combust. Inst. 28 (2000) 1639-1646.

[23] A. Cavaliere, M. de Joannon, Mild combustion, Prog. Energy Combust. Sci. 30 (2004) 329-366.

[24] A. Cuoci, A. Frassoldati, T. Faravelli, E. Ranzi, A computational tool for the detailed kinetic modeling of laminar flames: application to $\mathrm{C}_{2} \mathrm{H}_{4} / \mathrm{CH}_{4}$ coflow flames, Combust. Flame 160 (2013) 870-886.

[25] A. Cuoci, A. Frassoldati, T. Faravelli, E. Ranzi, Numerical modeling of laminar flames with detailed kinetics based on the operator-splitting method, Energy Fuels 27 (2013) 7730-7753.

[26] H. G. Weller, G. Tabor, H. Jasak, C. Fureby, A tensorial approach to computational continuum mechanics using object-oriented techniques, Comput. Phys. 12 (1998) 620-631.

[27] San Diego Mechanism web page, Mechanical and Aerospace Engineering (Combustion Research), University of California at San Diego, Chemical-kinetic mechanisms for combustion applications, http://combustion.ucsd.edu. 
[28] R. J. Kee, F. M. Rupley, E. Meeks, J. A. Miller, CHEMKIN-III: a fortran chemical kinetics package for the analysis of gas-phase chemical and plasma kinetics, SAND96-8216.

[29] S. K. Choi, S. Al-Noman, S. H. Chung, Simulation of non-autoignited and autoignited laminar nonpremixed jet flames of syngas in heated coflow air, Combust. Sci. Technol. 187 (2015) 132-147.

[30] G. P. Smith, D. M. Golden, M. Frenklach, N. W. Moriarty, B. Eiteneer, M. Goldenberg, C. T. Bowman, R. K. Hanson, S. Song, W. C. Gardiner, V. V. Lissianski, Z. Qin, GRI-Mech 3.0, http://combustion. berkeley.edu/gri-mech.

[31] H. Wang, X. You, A. V. Joshi, S. G. Davis, A. Laskin, F. Egolfopoulos, C. K. Law, USC Mech Version II. High-Temperature Combustion Reaction Model of $\mathrm{H}_{2} / \mathrm{CO} / \mathrm{C} 1-\mathrm{C} 4$ Compounds, http://ignis.usc.edu/USC_Mech_II.htm.

[32] E. L. Petersen, D. M. Kalitan, S. Simmons, G. Bourque, H. J. Curran, J. M. Simmie, Methane/Propane oxidation at high pressures: experimental and detailed chemical kinetic modelling, Proc. Combust. Inst. 31 (2007) 447-454.

[33] A. A. Konnov, Implementation of the NCN pathway of prompt-NO formation in the detailed reaction mechanism, Combust. Flame 156 (2009) 2093-2105.

[34] R. W. Bilger, The structure of turbulent nonpremixed flames, Symp. (Int.) Combust. 22 (1988) 475-488.

[35] E. Mastorakos, Ignition of turbulent non-premixed flames, Prog. Energy Combust. Sci. 35 (2009) 57-97.

[36] Y. C. Chen, R. W. Bilger, Stabilization mechanisms of lifted laminar flames in axisymmetric jet flows, Combust. Flame 123 (2000) 23-45.

[37] Y. Xue, Y. Ju, Studies on the liftoff properties of dimethyl ether jet diffusion flames, Combust. Sci. Technol. 178 (2006) 2219-2247.

[38] K. Gkagkas, R. P. Lindstedt, Transported PDF modelling with detailed chemistry of pre- and autoignition in $\mathrm{CH}_{4}$ /air mixtures, Proc. Combust. Inst. 31 (2007) 1559-1566.

[39] R. L. Gordon, A. R. Masri, E. Mastorakos, Heat release rate as represented by $[\mathrm{OH}] \times\left[\mathrm{CH}_{2} \mathrm{O}\right]$ and its role in autoignition, Combust. Theory Model. 13 (2009) 645-670.

[40] Y. Minamoto, N. Swaminathan, R. S. Cant, T. Leung, Reaction zones and their structure in MILD combustion, Combust. Sci. Technol. 186 (2014) 1075-1096.

[41] Z. Chen, V. M. Reddy, S. Ruan, N. A. K. Doan, W. L. Roberts, N. Swaminathan, Simulation of MILD combustion using perfectly stirred reactor model, Proc. Combust. Inst. 36 (2017) 4279-4286.

[42] T. Lu, C. S. Yoo, J. H. Chen, C. K. Law, Three-dimensional direct numerical simulation of a turbulent lifted hydrogen jet flame in heated coflow: a chemical explosive mode analysis, J. Fluid Mech. 652 (2010) 45-64.

[43] Z. Luo, C. S. Yoo, E. S. Richardson, J. H. Chen, C. K. Law, T. Lu, Chemical explosive mode analysis for a turbulent lifted ethylene jet flame in highly-heated coflow, Combust. Flame 159 (2012) 265-274. 
[44] R. Shan, C. S. Yoo, J. H. Chen, T. Lu, Computational diagnostics for n-heptane flames with chemical explosive mode analysis, Combust. Flame 159 (2012) 3119-3127.

[45] M. B. Luong, G. H. Yu, S. H. Chung, C. S. Yoo, Ignition of a lean PRF/air mixture under RCCI/SCCI conditions: Chemical aspects, Proc. Combust. Inst. 36 (2017) 3587-3596.

[46] A. Lifshitz, K. Scheller, A. Burcat, G. B. Skinner, Shock-tube investigation of ignition in methaneoxygen-argon mixtures, Combust. Flame. 16 (1971) 311-321.

[47] Y. Ju, T. Niioka, Ignition simulation of methane/hydrogen mixtures in a supersonic mixing layer, Combust. Flame. 102 (1995) 462-470.

[48] J. H. Chen, E. R. Hawkes, R. Sankaran, S. D. Mason, H. G. Im, Direct numerical simulation of ignition front propagation in a constant volume with temperature inhomogeneities I. Fundamental analysis and diagnostics, Combust. Flame. 145 (2006) 128-144.

[49] R. L. Gordon, A. R. Masri, S. B. Pope, G. M. Goldin, Transport budgets in turbulent lifted flames of methane autoigniting in a vitiated co-flow, Combust. Flame. 151 (2007) 495-511.

[50] A. Krisman, E. R. Hawkes, M. Talei, A. Bhagatwala, J. H. Chen, Polybrachial structures in dimethyl ether edge-flames at negative temperature coefficient conditions, Proc. Combust. Inst. 35 (2015) 9991006.

[51] R. Cabra, T. Myhrvold, J. Y. Chen, R. W. Dibble, A. N. Karpetis, R. S. Barlow, Simultaneous laser RamanRayleighLIF measurements and numerical modelling results of a lifted turbulent $\mathrm{H}_{2} / \mathrm{N}_{2}$ jet flame in a vitiated coflow, Proc. Combust. Inst. 29 (2002) 1881-1888.

[52] S. Deng, P. Zhao, M. E. Mueller, C. K. Law, Stabilization of laminar nonpremixed DME/air coflow flames at elevated temperatures and pressures, Combust. Flame 162 (2015) 4471-4478.

[53] A. Krisman, E. R. Hawkes, J. H. Chen, The structure and propagation of laminar flames under autoignitive conditions, Combst. Flame. 188 (2018) 399-411.

[54] O. Schulz, N. Noiray, Autoignition flame dynamics in sequential combustors, Combst. Flame. 192 (2018) 86-100.

[55] X. Gao, S. Yang, B. Wu, W. Sun, The effects of ozonolysis activated autoignition on non-premixed jet flame dynamics: a numerical and experimental study, $53^{\text {rd }}$ AIAA/SAE/ASEE Joint Propulsion Conference, 2017.

[56] O. Schulz, T. Jaravel, T. Poinsot, B. Cuenot, N. Noiray, A criterion to distinguish autoignition and propagation applied to a lifted methane-air jet flame, Proc. Combust. Inst. 36 (2016) 1-8.

[57] R. Sankaran, Propagation velocity of a deflagration front in a preheated autoigniting mixture, $9^{\text {th }}$ US National Combustion Meeting (2015) paper 2E09.

[58] C. H. Gibson, Find structure of scalar fields mixed by turbulence. I. Zero-gradient points and minimal gradient surfaces, Phys. Fluids 11 (1968) 2305-2315. 
[59] T. Echekki, J. H. Chen, Structure and propagation of methanolair triple flames, Combust. Flame 114 (1998) 231-245.

[60] H. G. Im, J. H. Chen, Structure and propagation of triple flames in partially premixed hydrogenair mixtures, Combust. Flame 119 (1999) 436-454.

[61] H. S. Bak, S. R. Lee, J. H. Chen, C. S. Yoo, A numerical study of the diffusive-thermal instability of opposed nonpremixed tubular flames, Combust. Flame 162 (2015) 4612-4621.

[62] S. O. Kim, M. B. Luong, J. H. Chen, C. S. Yoo, A DNS study of the ignition of lean PRF/air mixtures with temperature inhomogeneities under high pressure and intermediate temperature, Combust. Flame 162 (2015) 717-726.

[63] R. Sankaran, E. R. Hwakes, C. S. Yoo, J. H. Chen, Response of flame thickness and propagation speed under intense turbulence in spatially developing lean premixed methaneair jet flames, Combust. Flame. 162 (2015) 3294-3306.

[64] H. S. Bak, C. S. Yoo, Flame instabilities and flame cell dynamics in opposed nonpremixed tubular flames with radiative heat loss, Combust. Flame 194 (2018) 322-333.

[65] S. Deng, P. Zhao, M. E. Mueller, C. K. Law, Autoignition-affected stabilization of laminar nonpremixed DME/air coflow flames, Combust. Flame 162 (2015) 3437-3445.

[66] R. W. Grout, A. Gruber, C. S. Yoo, J. H. Chen, Direct numerical simulation of flame stabilization downstream of a transverse fuel jet in cross flow, Proc. Combust. Inst. 33 (2011) 1629-1637.

[67] H. Kolla, R. W. Grout, A. Gruber, J. H. Chen, Mechanisms of flame stabilization and blowout in a reacting turbulent hydrogen jet in cross-flow, Combust. Flame 159 (2012) 2755-2766.

[68] M. B. Luong, Z. Luo, T. Lu, S. H. Chung, C. S. Yoo, Direct numerical simulations of the ignition of lean primary reference fuel/air mixtures with temperature inhomogeneities, Combust. Flame 160 (2013) 2038-2047. 